Article

\title{
Combinative Study of Urban Heat Island in Ascoli Piceno City with Remote Sensing and CFD Simulation-Climate Change and Urban Health Resilience-CCUHRE Project
}

\author{
Roberta Cocci Grifoni (D), Giorgio Caprari (D) and Graziano Enzo Marchesani *(D) \\ School of Architecture and Design, University of Camerino, 63100 Ascoli Piceno, Italy; \\ roberta.coccigrifoni@unicam.it (R.C.G.); giorgio.caprari@unicam.it (G.C.) \\ * Correspondence: graziano.marchesani@unicam.it
}

check for

updates

Citation: Cocci Grifoni, R.; Caprari,

G.; Marchesani, G.E. Combinative

Study of Urban Heat Island in Ascoli

Piceno City with Remote Sensing and

CFD Simulation-Climate Change

and Urban Health

Resilience-CCUHRE Project.

Sustainability 2022, 14, 688. https:/ /

doi.org/10.3390/su14020688

Academic Editor: Baojie He

Received: 30 November 2021

Accepted: 6 January 2022

Published: 9 January 2022

Publisher's Note: MDPI stays neutral with regard to jurisdictional claims in published maps and institutional affiliations.

Copyright: (c) 2022 by the authors. Licensee MDPI, Basel, Switzerland. This article is an open access article distributed under the terms and conditions of the Creative Commons Attribution (CC BY) license (https:/ / creativecommons.org/licenses/by/ $4.0 /)$.

\begin{abstract}
This paper presents a new methodological approach for analysing the impacts of climate change on the urban habitat and improving the quality of life for citizens. The study falls within the diagnostic phase of the Climate Change and Urban Health Resilience (CCUHRE) research project applied to the rationalist neighbourhood of Monticelli, a suburb of Ascoli Piceno (Italy). The methodological approach tests innovative and multidisciplinary cognitive tools to quantify the impacts of climate change and create refined risk maps combining remote sensing, spatial data, satellite images, and thermal fluid dynamic (CFD) simulations. These tools created an atlas of green areas and surfaces using scientific indexes that describe the relationship between the urban form and heat and between the type of ground and materials. The information yielded by geoprocessing will allow critical aspects in the context to be addressed with site-specific strategies. In fact, through downscaling, it is possible to analyse the thermal fluid dynamics characteristics of the most significant urban areas and identify the related weather/climate characteristics, perceptual scenarios, and thermal stressed regions. The results have provided a dataset that defines the degree of vulnerability of the neighbourhood and identifies the areas exposed to thermal risk.
\end{abstract}

Keywords: urban heat island; remote sensing; CFD analysis; urban thermal comfort; urban risk map

\section{Introduction}

It is well known that urbanized spaces suffer more from poor air quality and low environmental comfort [1-3] in general based on the microclimate conditions. The analysis of the microclimate characteristics on the urban scale and consequently the strategies and technologies capable of modifying it are fundamental for contrasting the adverse effects impacting the liveability and health of urban environments and the quality of outdoor and indoor spaces [4-6].

The CCUHRE (https:/ / sites.google.com/unicam.it/cchure/home accessed on 1 November 2021) (Climate Change and Urban Health Resilience) project [7] falls within the urbanplanning debate on healthy spatial planning, which addresses the relationships between city/urban form and citizens' health/well-being. This research is centered mainly on environmental/health questions tied to the impacts of climate change in cities and, in general, on the quality of life in urban habitats in relation to specific urban planning and social conditions.

In this paper, a transdisciplinary approach was used to develop a method of transscalar investigation to estimate/simulate the effects of climate change through digital processing and innovative geo-informatics tools referring to GIScience [8-10] and CFD (computational fluid dynamics) [11-13], which accompanied more traditional multi-system urban-planning analysis. In particular, remote sensing methods and processes were used to identify urban heat islands (UHI) on the neighbourhood scale based on medium-low spatial resolution images on which there is wide literature [14]. In a constant macro-micro dialogue, 
further medium-high data resolution investigations were based on digital terrain models (3d) and simulation algorithms in a GIS environment, as shown in some studies [15].

Therefore, the project was conducted with a mix of methods in which technological aspects were configured as a multi-objective tool, especially in the diagnostic and analytical phases. The investigations, tools, and methods presented here were applied to the case study of Monticelli, a rationalist neighbourhood and suburb of Ascoli Piceno, a city in the middle of Italy, which is particularly meaningful for the urban layout and sociodemographic conditions.

Although the case study tested innovative and multidisciplinary cognitive tools to build expert/technical knowledge- the object of this contribution-it is likewise important to underline how the CCUHRE project also contemplated different 'moments of listening' in the community to acquire opinions, recommendations, and general in-depth knowledge about the neighbourhood. This knowledge was obtained through questionnaires (the questionnaires administered to part of the community reviewed the strengths and weaknesses of the neighbourhood concerning safety inside and outside of buildings, the quality of life inside buildings, internal travel and connections to the city, and opportunities for socializing in the neighbourhood), focus groups (three focus groups involving residents and city representatives were organized. The encounters yielded criticalities, risks, opportunities, and desires related to three topics: movement and mobility, green areas and environmental quality, and places for interaction and sociality), and in-depth interviews (in synergy with the Marche Regional Health Authority (ASUR) Area Vasta 5 Ascoli Piceno-San Benedetto del Tronto, a heterogeneous sample of residents were interviewed to provide information about their state of health and daily habits. The interviewees were drawn from the register of residents or indicated by themselves as being experts in the area) that rendered the 'voice' of the community and certainly added value to the process of co-producing knowledge to devise interventions for urban regeneration and climate adaptation in concert with citizens [16].

This theoretical, applied, and in-the-field approach, which falls under the context of the neighbourhood and the people who live there, produced a public health and climate/morphological profile helpful in formulating new adaptive measures to mitigate temperature, improve outdoor thermal comfort and quality of life, and speculate evolutionary scenarios in line with the residents' needs and expectations.

To this end, this research tested a valuable combined method for identifying the areas with the most structural criticalities and social fragility (GIScience) on the urban scale. Further micro-scale (CFD) investigations were made to support the construction of adaptive guidelines based on the morphological specifics of the neighbourhood.

The combined approach (GIScience-CFD analysis) aims to feed the theoretical and application frame of reference on the issue of city/health, proposing a procedural and technological approach capable of highlighting the worst critical aspects and responding with citizens' proactive contribution. In addition to being involved in the moments mentioned above of 'audience/engagement', the residents of Monticelli will also be involved in positioning sensors and using an app to obtain feedback and data on climate comfort perceived within open/closed space neighbourhoods.

As shown in various studies [17-19], mostly on the micro scale, it is possible to calibrate computer models starting from monitoring and surveying campaigns of the incident environmental variables. To this aim, a surveying system will be placed at strategic points around the neighbourhood based on the map resulting from the combined GIScience-CFD analysis, to assess weather/climate information and air pollution data. The smartphone application processes data acquired in real-time to obtain information about the state of comfort and provide feedback.

These on-site measurements were functional for citizen engagement and raising awareness of emerging climate issues, but was not useful for properly calibrating the climate scenario. To this end, due to the lack of accuracy/reliability of the data received, the 
micro-simulation models were based on the climate data relating to the most representative day $[20,21]$.

Nevertheless, this digitized system generated an indispensable database for the study and planning of the neighbourhood. The active participation of citizens has helped raise awareness about the local effects of global climate change and laid the groundwork for future research between theoretical-applied research and field trials. This study can show that the social component guides and informs the analytical and design processes.

With a view to greater climate and social resilience where access to services, equity, liveability, and widespread quality are set as cardinal objectives in reconfiguring open spaces, the techniques and tools used for the risk assessment are outlined, with a specific focus on the urban heat island.

\section{Materials and Methods}

\subsection{Remote Sensing and Thermal Fluid Dynamics Simulation: A Combined Study for Risk Assessment}

The most authoritative scientific organizations (Intergovernmental Panel on Climate Change-IPCC, Centro Euro Mediterraneo sui Cambiamenti Climatici-CMCC, Urban Climate Change Research Network-UCCRN, European Environment Agency-EEA, etcetera.) invite a change in paradigm to address the environmental/climate change that will inevitably affect important socioeconomic, migratory, and health issues on a global scale [22-25]. These issues currently constitute the international socio-political frame of reference. The substantial changes we need to make would hopefully depend mainly on international climate agreements, respect for the commitments made by governments, and thus the quality of decisions and forward-thinking of decision-makers. In this view, it is therefore necessary to support the choices and better direct them with innovative studies $[26,27]$ that analyse urban dynamics with respect to space and time and the macro-micro scales, i.e., investigating both climate-altering impacts and those altered by global warming (global mitigation scale), and the local impacts of 'extreme events' which cities are now subject to with a certain regularity (local adaptation scale). In this perspective of going beyond common regional weather/climate scenarios, CCHURE has redeveloped the analysis strategy for 'impact chains' (the suggested workflow analyses urban structures/infrastructure and dominant social factors by relating the awareness of vulnerable population groups to the exposure of the city neighbourhood system to critical climatic conditions to which it is potentially subject) [25], adapting it to the local context and available data to assess the relationships between city form, potential climate-related impacts, and discomfort in terms of health and quality of life. More specifically, the analysis addressed the social and structural fragility of the neighbourhood regarding the degree of surface impermeability, land use and consumption, the incidence/temporality of climate events, urban form, the extent/type of natural areas, and localization of vulnerable swaths of the population, etc.

The preliminary digital graphics of the neighbourhood were produced in the GIS (geographic information system) environment with remote sensing and spatial analysis techniques. The data were synthesized in an urban risk map that identifies the areas with the greatest vulnerability to thermal stress and urban run-off.

This process enabled the development of scientific indices related to bioclimatic comfort perceived on-site by a hypothetical resident with standardized environmental parameters and represents the state of comfort and health in a single index, i.e., the UTCI index [28-30], appropriately relating environmental variables and variables related to the person. This comfort index is based on perceived temperature. It was calculated using the specific tool Biomet, contained in ENVI-met [31,32], which systemizes air temperature, wind speed, average radiant temperature, and humidity.

The information collected in the GIS archives, such as shape and size of the buildings, position and type of green areas, soil permeability and traffic information, were used to carry out BIM (building information modelling (building information modeling is a method for managing building construction and manipulation processes in which relevant data 
can be collected, combined, and linked by correlating geometric and semantic space) that returns the three-dimensional nature. Thermo-fluid dynamics simulations using CFD (computational fluid dynamics) were made using the ENVI-met software. Given the parametric nature of the GIS archives, the parametric development platform Grasshopper (a visual programming language tool allows software to be generated through a simplified interface in which the user) was used, allowing for dynamic adaptation to the GIS information and microclimate characteristics of the area [33]. Thermal fluid dynamics simulations yield results that easily identify urban overheating of most susceptible areas [34].

The qualitative/quantitative geo-information approach led to the construction, management, and visualization of a georeferenced database that can be updated over time, allowing the studies to be shared with the various stakeholders through Web-GIS or other ICT applications. Therefore, the GIS approach underlies the project itself and its goal of the application, becoming essential for downscaling climate models, reducing the field of action, and identifying target/critical areas for intervention (Figure 1).

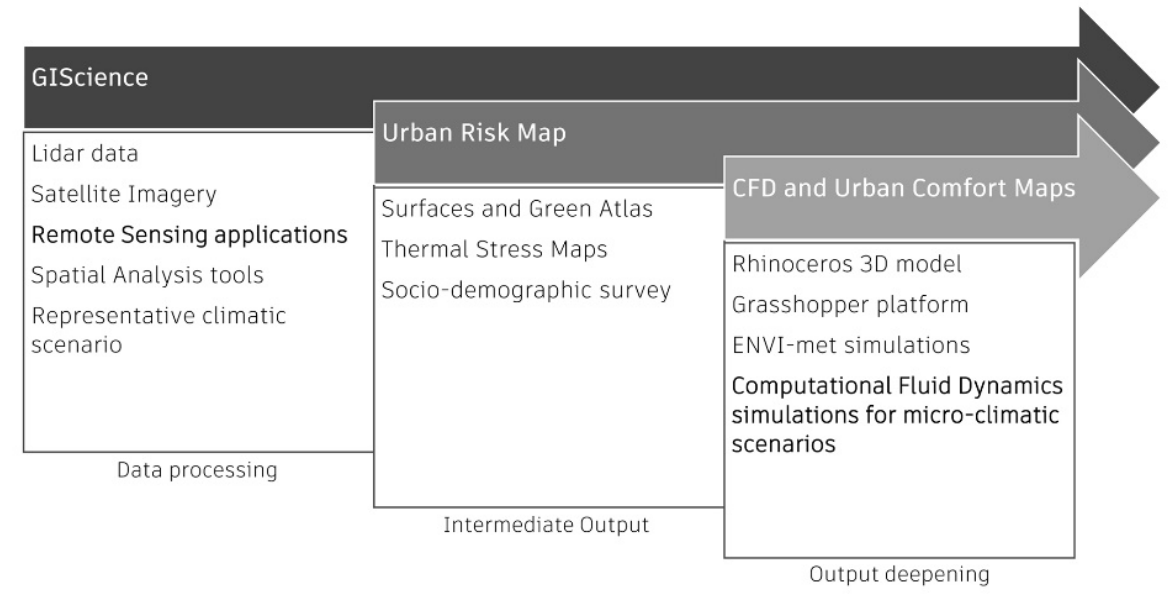

Figure 1. Summary of the technological workflow: from macro to micro scales.

\subsection{The Case Study: Monticelli and Its Climate Scenario}

The Monticelli district, planned by Leonardo Benevolo and developed from the 1970s onwards, is an example of a rationalist district, even if not entirely built, inspired by the principles and concepts of the modern movement. The same volumetric, hierarchical, and functional characteristics of the different spaces and axes that still define the urban layout and the peri-urban landscape at the gates of Ascoli Piceno (Figure 2a,b) today constitute a potentially fertile ground for experimentation within the scope of urban and social regeneration [35]. The experiments conducted under CCUHRE are configured as analytical and methodological, but nevertheless materialize as evolutionary/adaptive actions thanks to the sizing of the full/empty spaces, the relationship with the Tronto River, resident requests, and the appearance of an indefinite/incomplete place ready to welcome a potential reconfiguration, especially of open spaces.

Beyond the technical/spatial aspects, the socio-perceptive component returned by the inhabitants or experts during the different opportunities for listening/interaction mentioned above also helped to focus attention on this portion of the territory. The neighbourhood hosts different recreational and social possibilities/activities related to sports and leisure, but it is perceived as a dormitory, inhabited yet isolated from the rest of the city. Despite some timid attempts at social cohesion and community life, Monticelli looks to be-and still is - an area of crossing along the longitudinal east-west axis. As a neighbourhood physically still on edge, it apparently functions as an entrance to and exit from the city. Similar to many peripheral areas, it presents various criticalities and resources in which the citizens identify themselves and from which it is necessary to start again. 


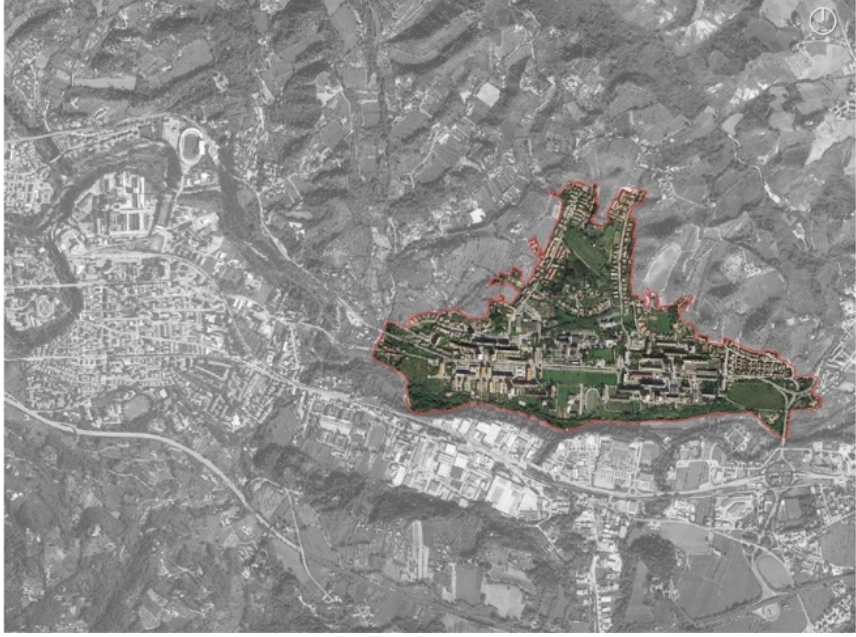

(a)

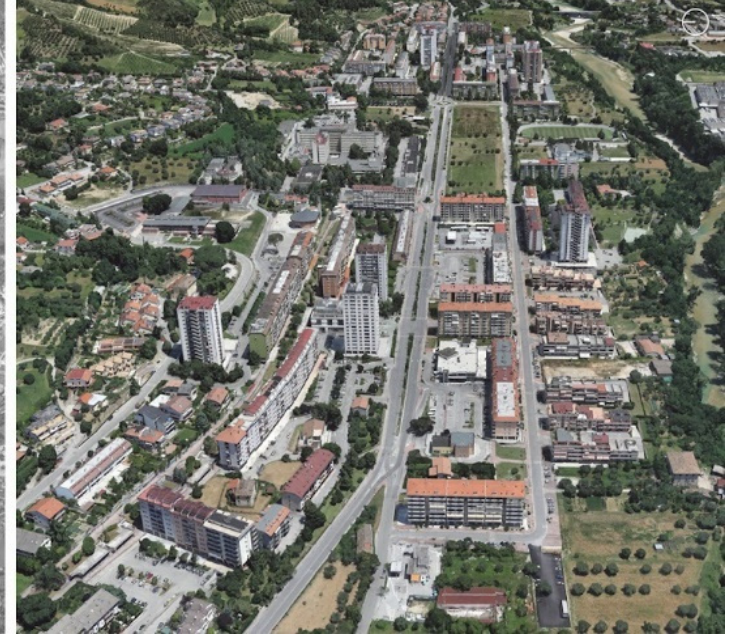

(b)

Figure 2. (a) Frame of the rationalist district of Monticelli on the outskirts of Ascoli Piceno; (b) detailed view of the central longitudinal axis (W-E direction). Basemap source: Google Maps and Google Earth.

Widespread deterioration, the scarcity of quality public/private services and a general lack of a unified vision in line with contemporary emergencies and the needs of citizenship seem to pervade the sense of abandonment and insecurity perceived by observing the territory and listening to the community. The community currently has about 8000 residents (out of 46,760 in the entire city; source: ISTAT, National Institute of Statistics. Census of the population as of 1 January 2021), who have shown themselves, albeit in the limited sample of active, participating citizens, to be interested and open to dialogue and confident about a possible bottom-up renewal agreed upon with expert and local knowledge.

In sum, considering the socio-demographic, aesthetic-perceptive, morphological, and historical-architectural aspects mentioned above, it is possible to consider Monticelli (Even in terms of territorial extension, Monticelli represents about $1 / 8$ of the artificial surface of the entire municipality of Ascoli Piceno, constituting a sufficiently representative urban transept. Source: data processing starting from level 1 of the CLC-Corine Land Cover, ISPRA- Istituto per la Protezione e Ricerca Ambientale, CLC-2018; https: / groupware. sinanet.isprambiente.it/uso-copertura-e-consumo-di-suolo/library/copertura-del-suolo/ corine-land-cover / corine-land-cover-2018-iv-livello; accessed on 29 December 2021) as a transept of considerable interest. In this sense, Monticelli is representative of the linear valley urban system of the Tronto along which the city has developed. In addition to the social and natural aspects that characterize the neighbourhood, the area is also subject to different planning/programmatic provisions regarding road assets and social-residential aspects that feed its urban interest.

In line with the goals of the project, a process of regeneration can only be triggered after having entirely understood not only the social and experiential dynamics but also those related to morphology and meteorology, which are the subject of this contribution.

In this sense, the weather/climate characteristics of the Monticelli neighbourhood are also representative of the evolution of the climate scenario of Ascoli Piceno and, in general, the entire Marche Region (Italy). Indeed, an increase in average temperatures has been seen over the years, both in winter and summer, with 2019 being the seventh consecutive year warmer than average (historical period of reference 1981-2010, ASSAM, 2020). Likewise, in line with increasing temperature trends, the winter of 2020 was one of the warmest on record, with an anomaly of $+2.1^{\circ} \mathrm{C}$ compared with the average. These analyses show how the local effects of global climate change are evident for the Marche region and the Monticelli area. The temperature, humidity, and radiation graphs (shown in Figures 3-5) were processed with the ' $\mathrm{CBE}$ ' (The $\mathrm{CBE}$ climate tool is a web utility to display statistics and 
graphs from EPW files). The representative microclimatic scenario was evaluated using the representative day technique, which yields a characteristic summer meteorological scenario (Figures 6-8) using actual data from days in the selected period. The 'representative day' $^{\prime}[20,21]$ is a $24 \mathrm{~h}$ data set, actually recorded at a field station characterized by the fewest differences with respect to all $24 \mathrm{~h}$ measurements in the time series of that station, in other words, the daily series whose sum of the squared differences over $24 \mathrm{~h}$ is the smallest compared with all other days in the period considered. It consists of the actual data of the day in the period considered. This technique involves minimizing the sum of the mean squared differences between the monitored quantities averaged within each hour and the same quantities for all other days at the same time. Using the representative day method rather than the average day allows real scenarios to be used. The representative day for the hot scenario in recent years for Ascoli Piceno is 26 June 2017; Table 1 shows the numerical data.

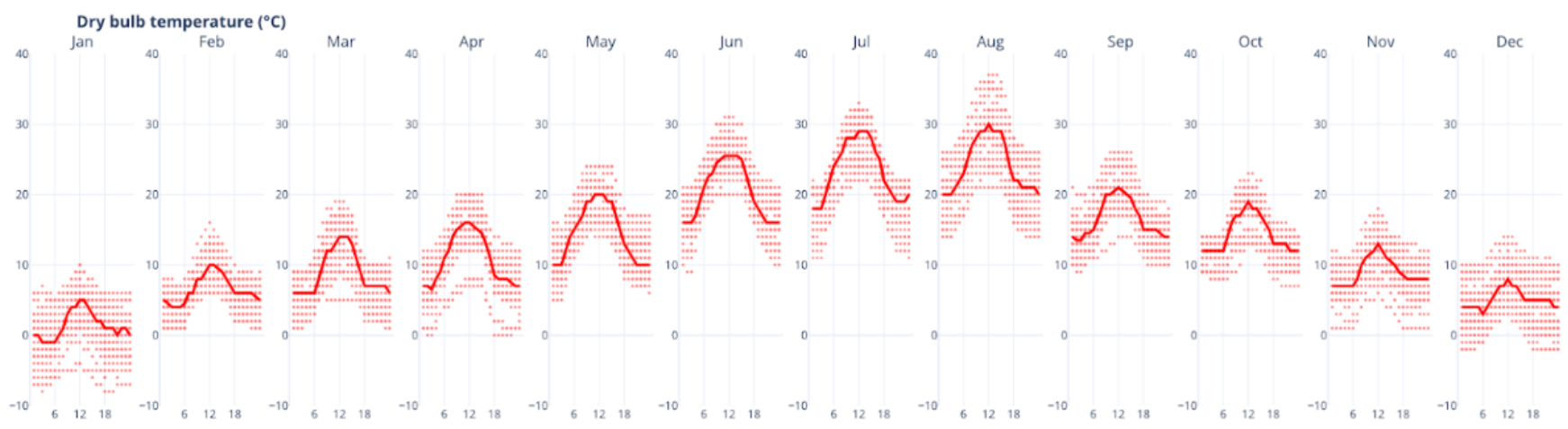

Figure 3. Dry bulb temperature-Ascoli Piceno, 2017.

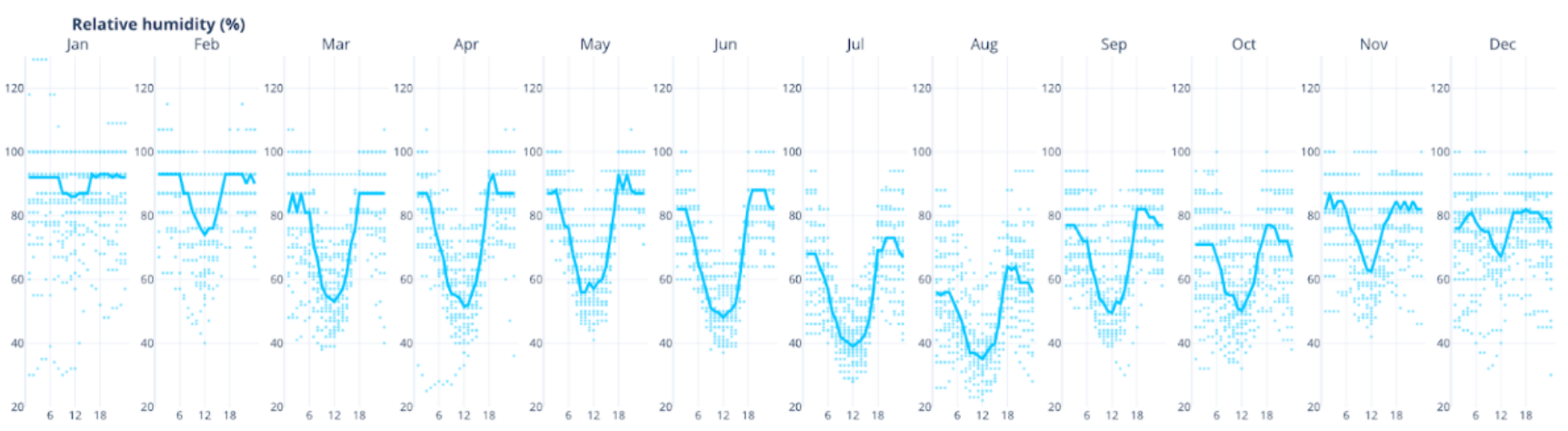

Figure 4. Relative humidity—Ascoli Piceno, 2017.

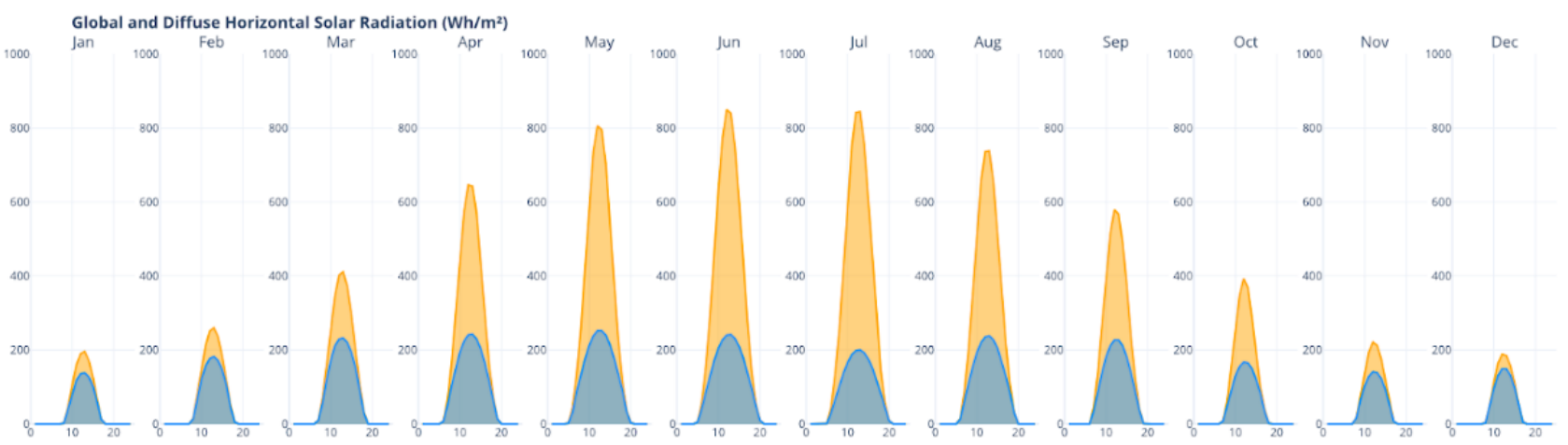

Figure 5. Global and Diffuse solar radiation-Ascoli Piceno, 2017. 
Representative day

$26 / 06 / 2017$

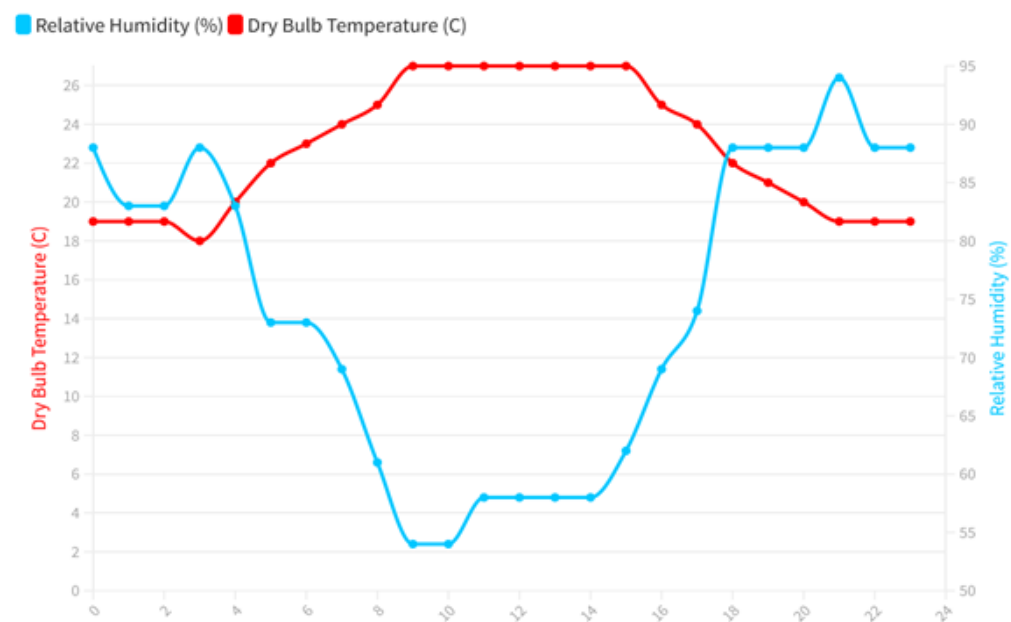

Figure 6. Dry bulb temperature and relative humidity-Ascoli Piceno, 26 June 2017.

\section{Representative day}

$26 / 06 / 2017$

Direct Normal Radiation (Wh/m2) Diffuse Horizontal Radiation (Wh/m2)

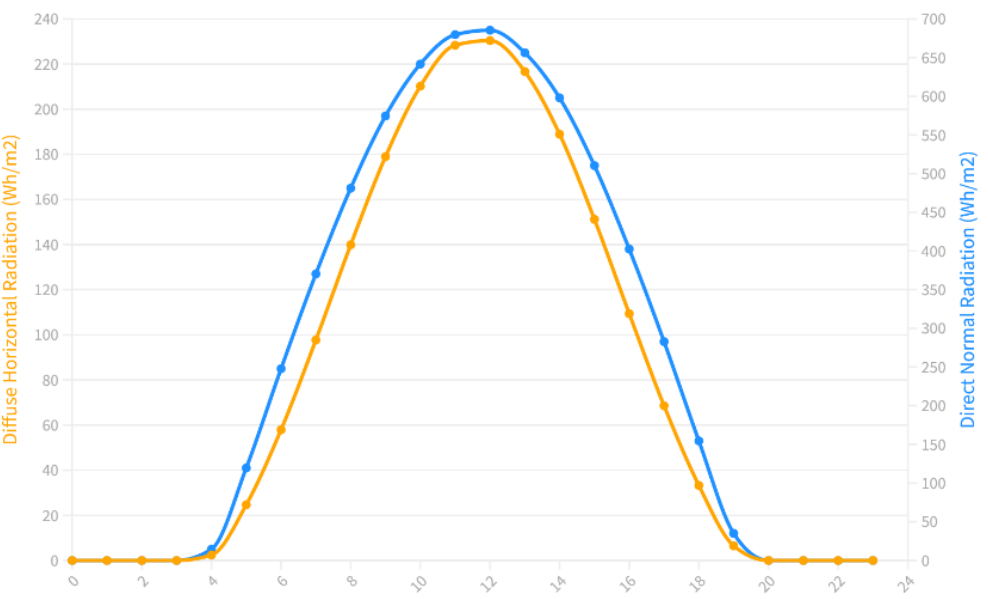

Figure 7. Direct and diffuse solar radiation-Ascoli Piceno, 26 June 2017.

Table 1. Meteorological data for the representative day.

\begin{tabular}{|c|c|c|c|c|c|c|}
\hline Hour & $\begin{array}{c}\text { Dry Bulb } \\
\text { Temp. }\left({ }^{\circ} \mathrm{C}\right)\end{array}$ & $\begin{array}{c}\text { Relative } \\
\text { Humidity (\%) }\end{array}$ & $\begin{array}{l}\text { Wind Speed } \\
(\mathrm{m} / \mathrm{s})\end{array}$ & $\begin{array}{l}\text { Wind Direction } \\
\text { (degrees) }\end{array}$ & $\begin{array}{l}\text { Direct Normal } \\
\text { Rad. }\left(\mathrm{Wh} / \mathrm{m}^{2}\right)\end{array}$ & $\begin{array}{l}\text { Diffuse Horizontal } \\
\text { Rad. }\left(\mathrm{Wh} / \mathrm{m}^{2}\right)\end{array}$ \\
\hline \multicolumn{7}{|l|}{$\ldots$} \\
\hline 9 & 27 & 54 & 1.9 & 59 & 522 & 197 \\
\hline 10 & 27 & 54 & 2.2 & 63 & 613 & 220 \\
\hline 11 & 27 & 58 & 2.5 & 67 & 666 & 233 \\
\hline 12 & 27 & 58 & 2.8 & 71 & 672 & 235 \\
\hline 13 & 27 & 58 & 2.8 & 74 & 632 & 225 \\
\hline 14 & 27 & 58 & 2.5 & 77 & 551 & 205 \\
\hline 15 & 27 & 62 & 2.5 & 80 & 441 & 175 \\
\hline 16 & 25 & 69 & 1.9 & 87 & 319 & 138 \\
\hline 17 & 24 & 74 & 1.7 & 94 & 200 & 97 \\
\hline 18 & 22 & 88 & 1.1 & 101 & 97 & 53 \\
\hline$\ldots$ & & & & & & \\
\hline
\end{tabular}




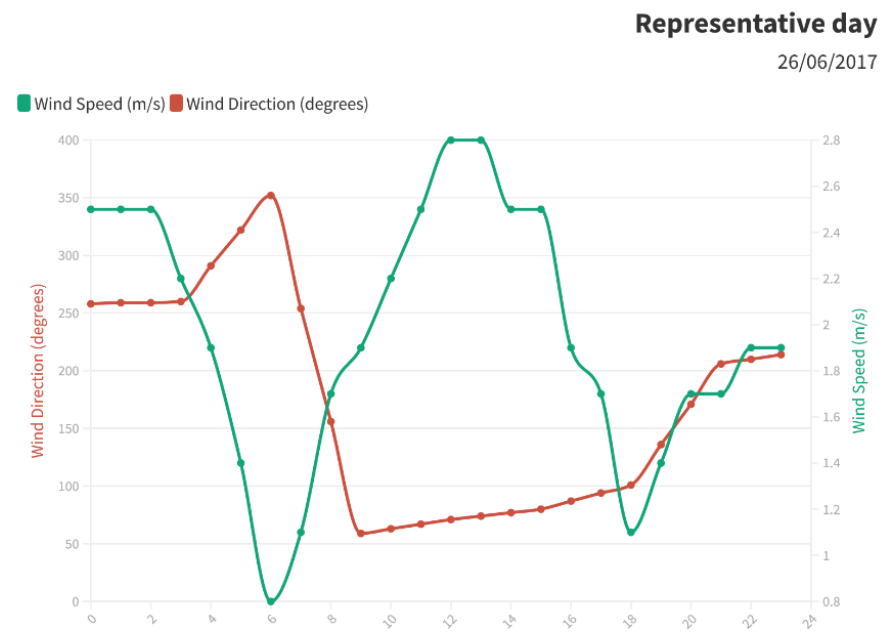

Figure 8. Wind speed and direction-Ascoli Piceno, 26 June 2017.

\subsection{Initial Data and Data Processing}

To analyse urban fragility and vulnerabilities and create the scientific indices and the geo-information dataset, various types of open access/open source and proprietary data were used:

- Digital AgEA (Agenzia per le Erogazioni in Agricoltura) orthophoto from 2016 with a geometric resolution of $20 \mathrm{~cm} / \mathrm{px}$ (The Agea 2016 orthophotos were provided by the City of Ascoli Piceno, Sector 8-Urban Planning, TIS, and European policies, and used in compliance with the use licence);

- Digital surface model (DSM) and digital terrain model (DTM) produced using LiDAR technology, geometric resolution of $1 \mathrm{~m} / \mathrm{px}$ (The data are the property of the Ministry of the Environment and Protection of the Land and Sea, in Italian, MATTM, now the Ministry of the Ecological Transition, and were used in compliance with the licence);

- Landsat 8 (bands 10 and 11, thermal infrared sensor TIRS) with a geometric resolution of $30 \mathrm{~m} / \mathrm{px}$;

- Multispectral IKONOS images with a geometric resolution of $0.8 \mathrm{~m} / \mathrm{px}$;

- Demographic census of Monticelli provided by the City of Ascoli Piceno, updated 2018;

- A thematic layer regarding the profile of the built area, acquired using Web Feature Service (WFS) (http:/ / www.pcn.minambiente.it/mattm/servizio-di-scaricamentowfs / accessed on 22 July 2021);

- Shapefiles of the Monticelli area provided by the City of Ascoli Piceno;

- Weather data related to past scenarios acquired from World Weather Online.

Initial data-processing regarded the entire quarter, including the surrounding periurban and natural areas. More specifically, the initial geo-processing was aimed at semiautomatically and scientifically identifying the green areas within the neighbourhood via remote sensing. The mapping was made possible by calculating a vegetation index (soil-adjusted vegetation index, SAVI), i.e., processing NIR (near-infrared) and RED electromagnetic bands of the multispectral IKONOS images in the GIS environment using the formula:

$$
\mathrm{SAVI}=((\mathrm{NIR}-\mathrm{RED}) /(\mathrm{NIR}+\mathrm{RED}+\mathrm{L})) \times(1+\mathrm{L}),
$$

where $\mathrm{L}$ is a regulation factor with a value of 0.5 in the scientific literature [36] used to minimize atmospheric influences on the luminosity of the land, especially in areas where there is little vegetation (arid land, urban areas, etcetera.). The index thus calculated (Figure 9) returns a raster format ranging from -1 to 1 of the distribution of green areas on the date the image was acquired. This procedure led to a distinction between the natural and anthropic components of Monticelli identified and differentiated through the 'spectral signature' of the elements on the terrain (vegetation, agricultural fields, buildings, 
roads, etcetera.). The resulting file was reclassified based on the surface category: green infrastructure (permeable) and grey infrastructure (impermeable).
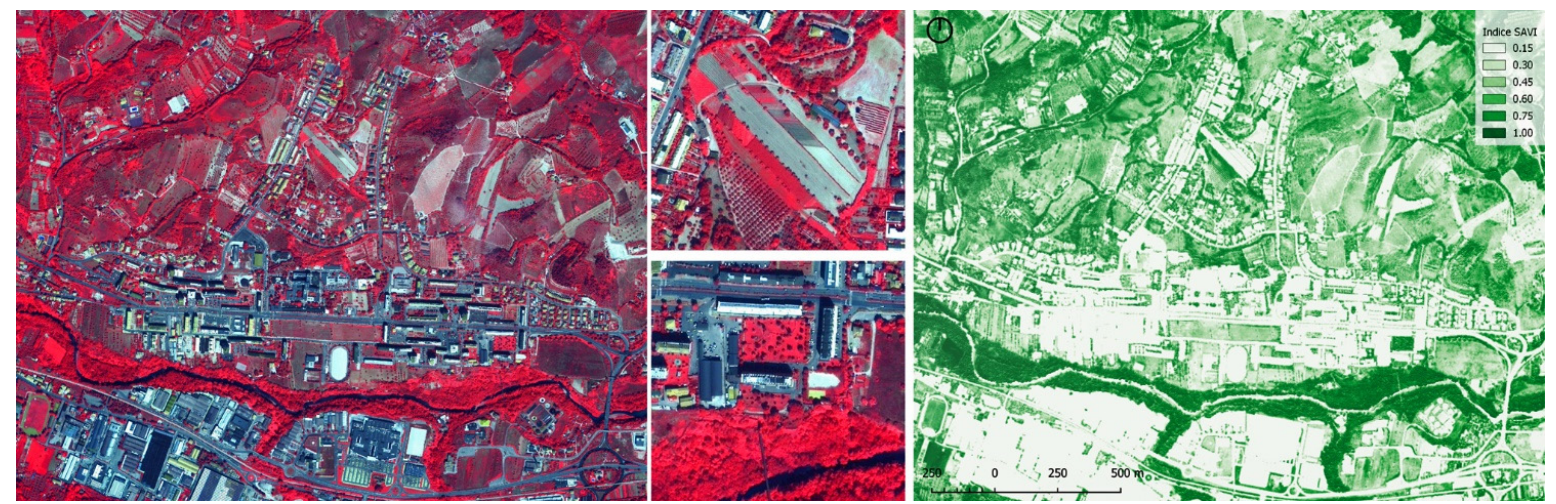

Figure 9. False-colour multispectral IKONOS image (11 August 2006) and the soil-adjusted vegetation index, SAVI. In the upper detail, a field cultivated during the rotation period is highlighted, as it is bare soil; the semi-automatic calculations consider it waterproof.

This process is configured as a Surface Atlas and a preliminary phase in creating the Urban Green Atlas, which is presented in the next section.

The research has specifically addressed heat, proceeding with the urban vulnerability assessment, and using other scientific indices based on satellite indices or simulations. The first investigation again relied on remote sensing tools, starting with measured data and various mathematical formulas $[37,38]$ to convert the digital number (DN) of Landsat 8 image pixels into the atmospheric radiance, the temperature at the satellite, the emissivity of terrestrial surfaces, and the temperature at the ground. This process yielded the LST (land surface temperature) index, which allowed the temperature referring to the urban vault above the average height of the buildings (urban boundary layer) measured by the satellite to be read on a specific date/time. The output in temperature expressed in Celsius depends on anthropogenic factors, the type of soil and materials (albedo, reflectance, etc.), as well as the presence/type of green or forested areas (leaves, humidity, etc.) [39,40]. This macro-scale processing was related to three days in the summer of 2017 (the following days were selected: 13 June, 31 July, and 16 August 2017. The choice of period and year depended on the weather reports consulted, whereas the days refer to the availability of satellite images, which can be obtained free of charge from https:/ / earthexplorer.usgs.gov/ accessed on 1 November 2021) (Figure 10), where regional weather bulletins [41] were identified as the second hottest in the last fifty years (http:/ / www.meteo.marche.it/news/ anno2017/clima2017.pdf (accessed on 1 November 2021)). The analysis, therefore, returns the system of urban/territorial areas most subject to thermal stress, which are associated with further site-specific investigations using both algorithms within GIS software and CFD applications in the ENVI-met environment.

Addressing the thermal simulations in the GIS environment required two key steps: (i) processing the DSM to obtain the heights of urban elements (vegetation, buildings, etc.) for the ground and not just compared with the average sea level; (ii) developing intermediate output tied to the urban morphology (system of buildings and open spaces) and bioclimate factors, the sky-view factor (SVF). The SVF indicates the portion of visible sky from the observation point; it is directly proportional to the amount of incident solar radiation. As shown in Kleerekoper (2012) [42], when the urban heat island is generated, a low SVF leads to a decrease in nocturnal radiation loss under weak wind conditions and a calm sky, especially when it is created within urban canyons. In contrast, a high SVF, usually related to open areas, would lead to the accumulation of heat, especially where it is asphalted/waterproofed with a low-albedo material. 


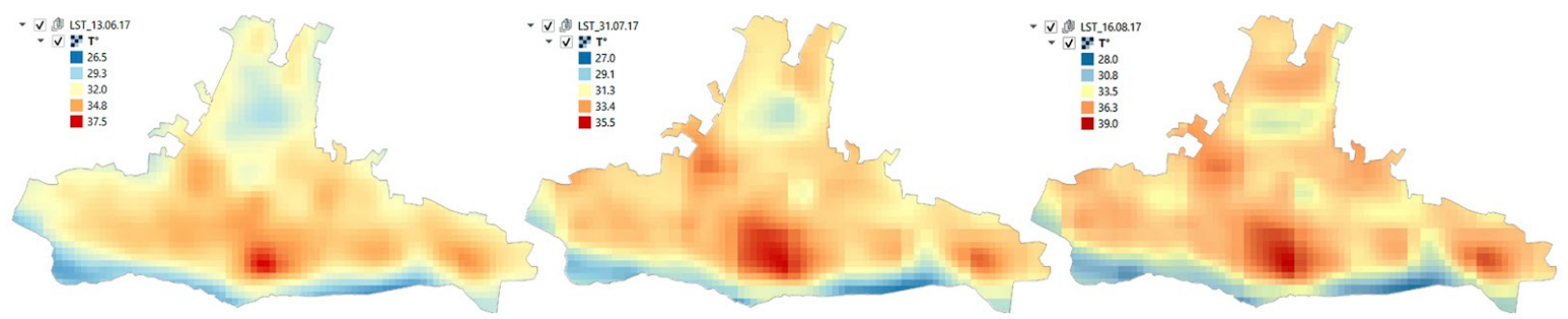

Figure 10. Land surface temperature of the three significant days selected: a thermal stress overview. Selected days from left to right: 13 June, 31 July, 16 August 2017.

Following this, a micro-scale simulation was made of the direct/diffuse solar radiation using two indices approved by the scientific community: global radiation (GR) and direct solar radiation (DSR), which require the DSM and SVF as input. The two indicators were calculated with a spatial analysis algorithm that quantifies the potential diurnal radiation of an area based on the geographic position, period/month/day, and selected time, especially in relation to the specific geomorphological and urban areas conformation (DSM). The processing allowed the amount of incident solar radiation between the ground and average building height, i.e., urban canopy layer (UCL), to be quantified $\left(\mathrm{kWh} / \mathrm{m}^{2}\right)$ with geometric detail of $1 \mathrm{~m} / \mathrm{px}$ (Figure 11).

This additional information, related to the LST, produced a cognitive framework of the thermal comfort/discomfort (the focus on UHI presented in this paper is also suggested by the significant increase in the average temperature in Ascoli in the last decade $\left(+2.1^{\circ}\right.$ compared with the 1960-70s), as shown by the research of the European Data Journalism Network, EDJNet 2020, available at: https: / climatechange.europeandatajournalism.eu/ en/italy/marche/ascoli-piceno/ascoli-piceno accessed on 1 November 2021) in the quarter, laying the basis for more detailed investigation of the areas highlighted as the most critical, not only due to the heat captured/generated but also due to the limiting presence of vulnerable residents (elderly people, widow(er)s, children, etc.), deriving first from ISTAT census data and then through specific demographic surveying.

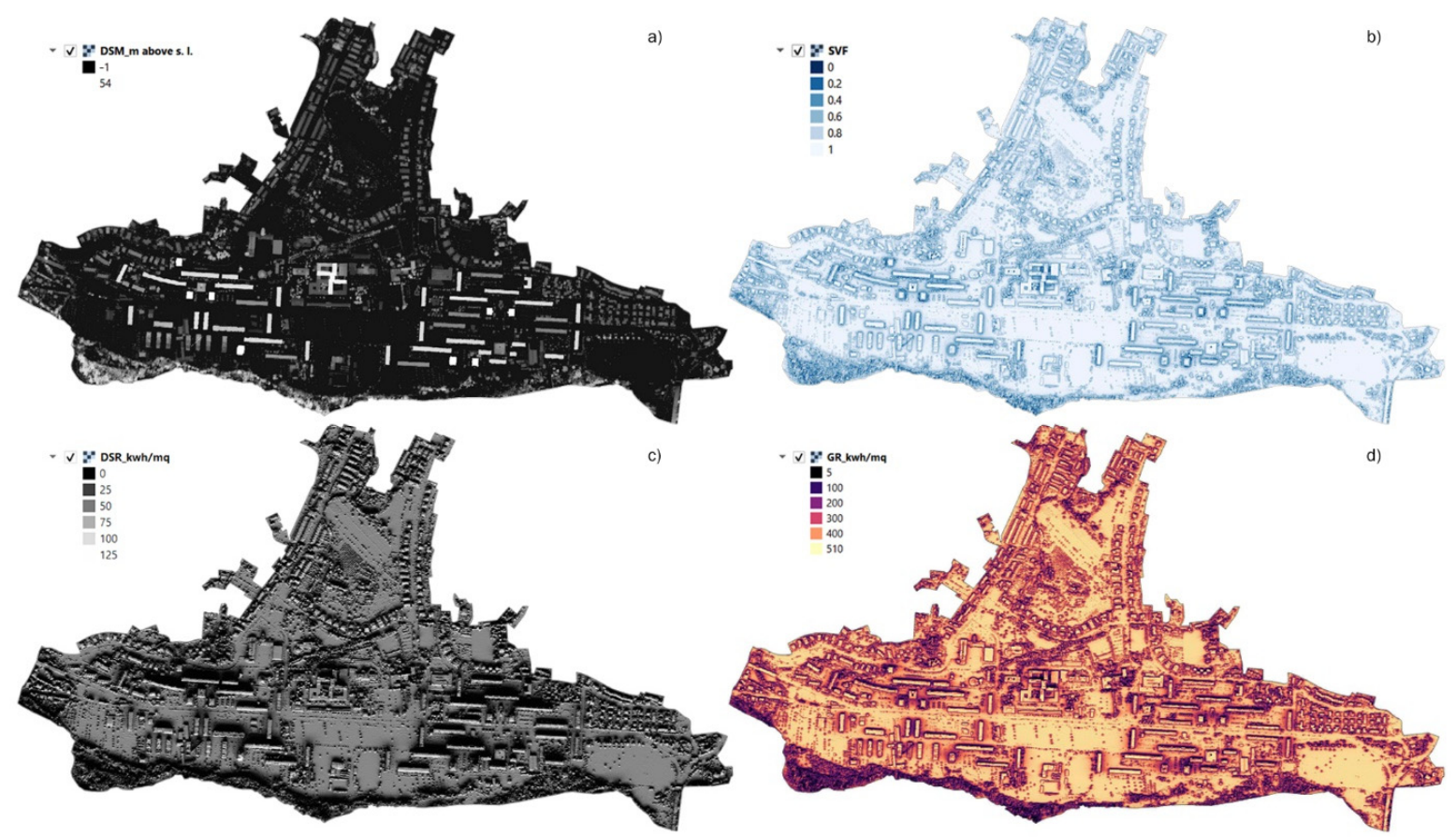

Figure 11. Correlation between the different Index: (a), DSM; (b), SVF; (c), DSR simulation in the winter period (December to February); (d), GR simulations in the summer period (June to August). 
The transcalar and combinative approach and the preliminary macro-scale analyses identified the three most vulnerable areas that can be analysed using CFD. These analyses in the GIS environment were functional to direct the subsequent investigations on some critical areas detected in the Monticelli district, preventing the dispersion of computational resources.

Focusing attention on these areas was indispensable for maintaining a balance between the levels of complexity of the analysis. Three three-dimensional models were reconstructed, starting with the digitized maps (Figures 12-14).

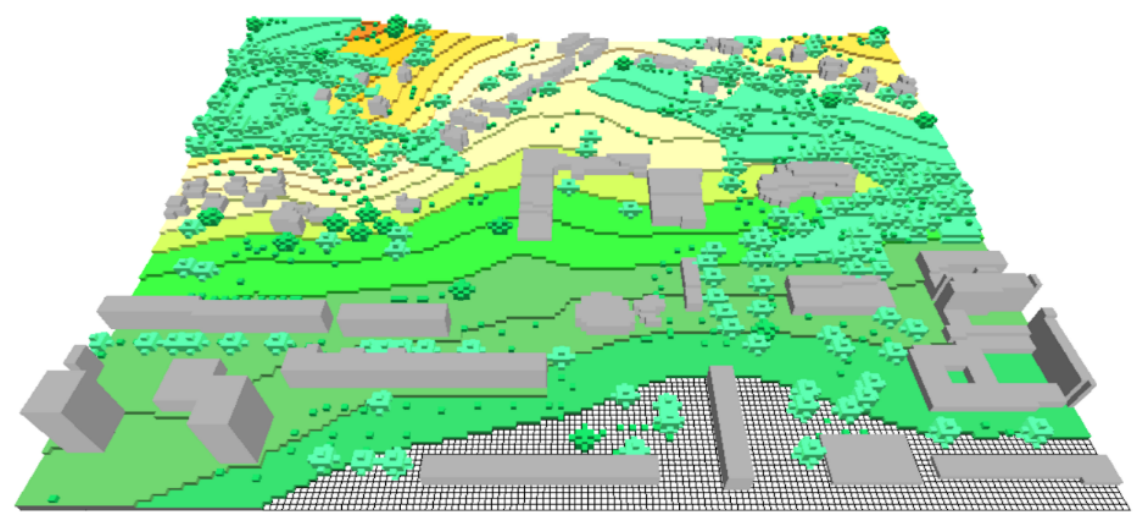

Figure 12. ENVI-met area: A.

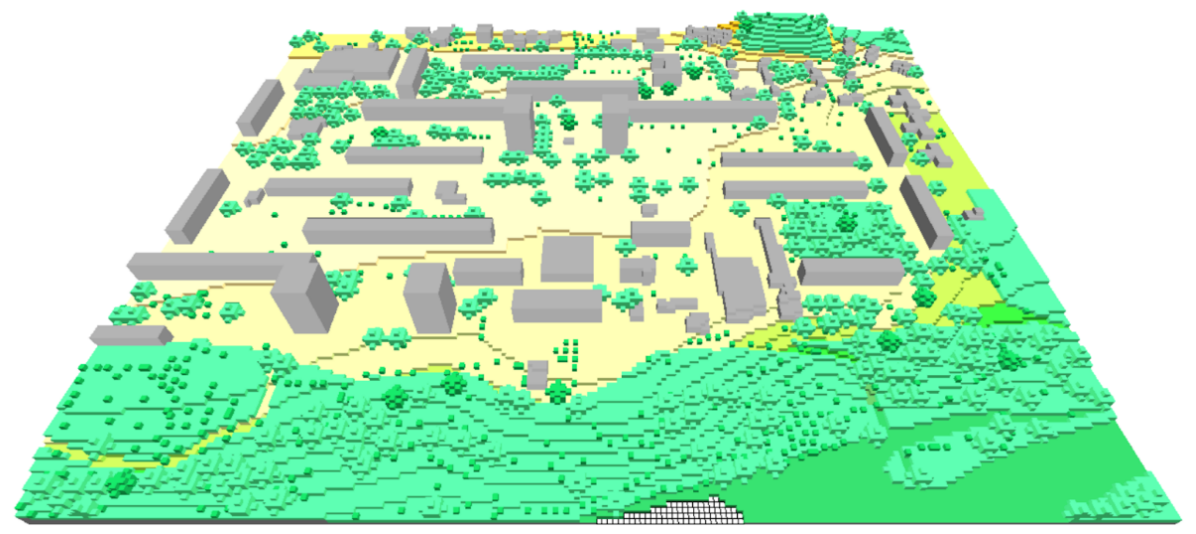

Figure 13. ENVI-met area: $\mathrm{B}$.

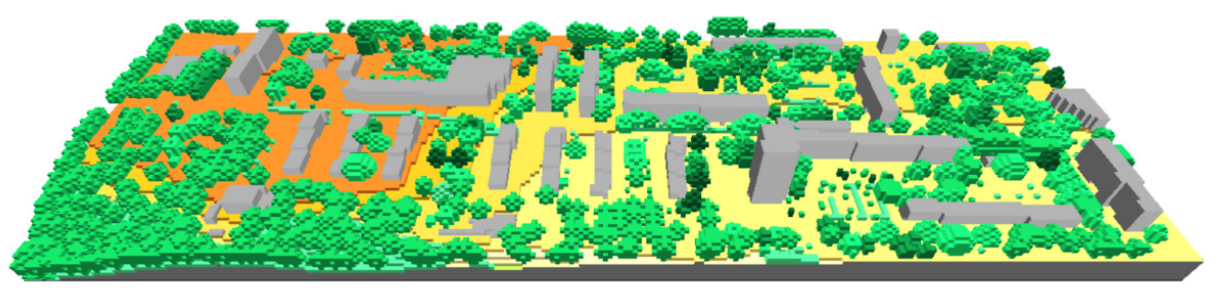

Figure 14. ENVI-met area: $\mathrm{C}$. 
These were converted into ENVI-met models through the Grasshopper visual programming platform using the Morpho application. Morpho is a Grasshopper plugin developed by Antonello di Nunzio that enables interaction with ENVI-met and proprietary algorithms (Figure 15). This development environment was indispensable for managing each aspect of exchange between the three-dimensional models and ENVI-met, acting in a parametric, reversible way in each process phase [43]. A cubic grid measuring $3 \mathrm{~m}$ at the side contained approximated geometries with a simplification to maintain similar building volumes, taking care to describe the constituent materials, ground materials, and vegetation (both low and tall). The dimensions of the three models are shown in Table 2. Altimetry data was used to render the terrain and obtain the morphology of the areas. Due to the geometric approximations made by the software, the relative corrections were made such that the morphology of the terrain would not alter the volumetric characteristics of the buildings. Following this, the definition of materials of the horizontal surfaces of the areas used data from satellite photos. Each material was identified by a specific colour, producing a vector diagram of the materials associated with each colour code (referring to the ENVI-met library). The next operation was to characterize the greenery present in the areas. The data were obtained from the analysis of aerial photos. Both tall and low vegetation is present in the areas. The tall vegetation was classified based on the size and characteristics of the species, whereas treatment of the low vegetation (grassland and crops) was similar to what was carried out for the ground materials. The physical properties of the materials used, and the vegetation is shown in Table 3. These data are from inspections and census of vegetation.

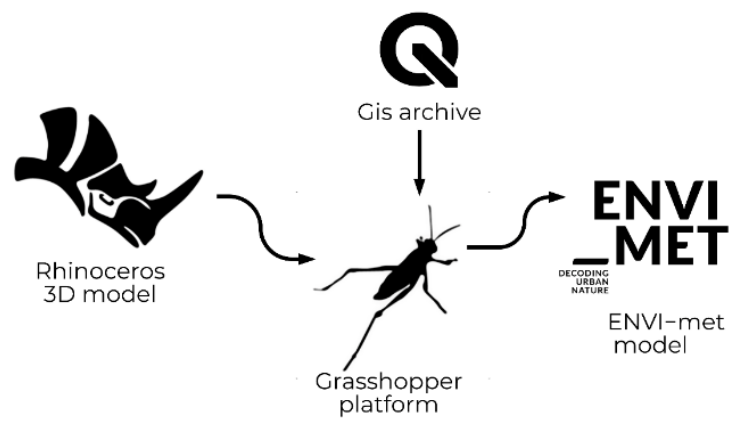

Figure 15. D model conversion into the ENVI-met model.

Table 2. ENVI-met model dimensions.

\begin{tabular}{ccccccc}
\hline Area & $\mathbf{d x}-\mathbf{d y}-\mathbf{d z}$ & $\mathbf{x}-$ Grid & $\mathbf{y}-$ Grid & $\mathbf{z}-$ Grid & Lat & Lon \\
\hline A & $3 \mathrm{~m}$ & 170 & 140 & 60 & 42.51 & 13.37 \\
B & $3 \mathrm{~m}$ & 210 & 160 & 60 & 42.51 & 13.37 \\
C & $3 \mathrm{~m}$ & 250 & 78 & 70 & 42.51 & 13.37 \\
\hline
\end{tabular}

Analysis with ENVI-met requires a twenty-four-hour set of continuous data, including information on temperature, humidity, wind speed, and direction. The well-established representative day method was used to derive this subset of data from a larger set using the Grasshopper platform. This consolidated algorithm can extract statistical information about the 'representative' day used to analyse the urban thermal fluid dynamics. This method uses a large data sample and traces both the day that best represents the hot scenario and the one that least describes it as an anomaly. The data sample analysed using the 'representative day' method relates to the hot scenarios (i.e., days where the average daytime temperature exceeds $25^{\circ} \mathrm{C}$ ) over the last five years, with temperature as the dominant variable. In addition to temperature, data on humidity, wind speed, wind direction, and shortwave and longwave radiation over the twenty-four hours of the representative day were entered into the system. The ENVI-met software uses all this information combined with geometric-material information and proprietary procedures to define the values of po- 
tential air temperatures, surface temperatures, average radiant temperatures, and the state of the wind over the hours simulated. Finally, the correlation between the partial results of the calculation produces a map of comfort indices, highlighting areas with criticalities, which can be addressed and resolved based on the considerations in this study.

Table 3. Soil and vegetation parameters used in ENVI-met model. ( ${ }^{*}$ Latin nomenclature correct with respect to the ENVI-met archive).

\begin{tabular}{|c|c|c|c|c|c|}
\hline Code & Description & Albedo & Roughness & Emissivity & LAD \\
\hline \multicolumn{6}{|c|}{ Profile materials } \\
\hline 0100AR & Asphalt road with red coating & 0.50 & 0.01 & 0.90 & - \\
\hline 0100BA & Basalt brick road & 0.80 & 0.01 & 0.90 & - \\
\hline 0100GS & Granite paving (single stones) & 0.40 & 0.01 & 0.90 & - \\
\hline 0100LO & Loamy soil & - & 0.02 & 0.98 & - \\
\hline 0100PG & Concrete pavement grey & 0.50 & 0.01 & 0.90 & - \\
\hline 0100PL & Concrete pavement light & 0.80 & 0.01 & 0.90 & - \\
\hline 0100ST & Asphalt road & 0.20 & 0.01 & 0.90 & - \\
\hline 0100WW & Deep water & - & 0.01 & 0.96 & - \\
\hline \multicolumn{6}{|c|}{$3 \mathrm{~d}$ plants } \\
\hline 000003 & Robinia pseudoacacia & 0.18 & - & - & 2.00 \\
\hline 0000A1 & Tilia cordata & 0.18 & - & - & 1.00 \\
\hline 0000A5 & Gleditsia triacanthos & 0.18 & - & - & 0.50 \\
\hline 0000A9 & Acer campestre & 0.18 & - & - & 2.00 \\
\hline 0000B2 & Fagus sylvatica & 0.18 & - & - & 1.50 \\
\hline 0000B3 & Quercus robur & 0.18 & - & - & 1.80 \\
\hline 0000B4 & Carpinus betulus & 0.18 & - & - & 2.00 \\
\hline 0000B5 & Fraxinus excelsior & 0.18 & - & - & 1.00 \\
\hline 0000B7 & Betula pendula & 0.18 & - & - & 0.90 \\
\hline 0000B8 & Platanus $\times$ acerifolia & 0.18 & & - & 1.10 \\
\hline 0000C3 & Abies alba & 0.18 & - & - & 0.70 \\
\hline 0000CC & Fraxinus sp. * & 0.60 & - & - & 1.00 \\
\hline 0000E1 & Ulmus minor & 0.18 & - & - & 1.00 \\
\hline $0000 J \mathrm{~J}$ & Cercis siliquastrum & 0.60 & - & - & 0.60 \\
\hline 0000K1 & Koelreuteria paniculata & 0.70 & - & - & 0.70 \\
\hline 0000LI & Ligustrum sp. * & 0.40 & - & - & 0.70 \\
\hline 0000OT & Olea europaea & 0.50 & - & - & 0.50 \\
\hline 0000PP & Pinus pinea & 0.60 & - & - & 1.50 \\
\hline 0000PW & Washingtonia sp. * & 0.60 & - & - & 0.50 \\
\hline 0000S2 & Sophora japonica & 0.60 & - & - & 0.40 \\
\hline 0000ZI & Citrus $x$ aurantium & 0.40 & - & - & 0.70 \\
\hline 0000ZY & Cupressus sp. * & 0.30 & - & - & 0.40 \\
\hline 01ALDL & Conic, large trunk, dense, large $(25 \mathrm{~m})$ & 0.12 & - & - & 2.30 \\
\hline 01ASDS & Conic, small trunk, dense, small $(5 \mathrm{~m})$ & 0.12 & - & - & 2.30 \\
\hline 01CMDS & Cylindric, medium trunk, dense, small (5 m) & 0.12 & - & - & 2.30 \\
\hline 01HMSS & Heart-shaped, medium trunk, sparse, small $(5 \mathrm{~m})$ & 0.18 & - & - & 0.30 \\
\hline 01OLDL & Cylindric, large trunk, dense, large $(25 \mathrm{~m})$ & 0.18 & - & - & 1.10 \\
\hline 01OMDM & Cylindric, medium trunk, dense, medium $(15 \mathrm{~m})$ & 0.18 & - & - & 1.10 \\
\hline 01PMDS & Palm, medium trunk, dense, small (5 m) & 0.60 & - & - & 0.60 \\
\hline 01SMDM & Spherical, medium trunk, dense, medium (15 m) & 0.18 & - & - & 1.10 \\
\hline 01SMDS & Spherical, medium trunk, dense, small (5 m) & 0.18 & - & - & 1.10 \\
\hline 01SSDS & Spherical, small trunk, dense, small $(5 \mathrm{~m})$ & 0.18 & - & - & 1.10 \\
\hline 01SSDS & Spherical, small trunk, dense, small $(5 \mathrm{~m})$ & 0.18 & - & - & 1.10 \\
\hline \multicolumn{6}{|c|}{ Simple plants } \\
\hline 0100XX & Grass $25 \mathrm{~cm}$ aver. dense & 0.20 & - & - & 0.30 \\
\hline
\end{tabular}

The IT team engineered data-collection devices in the monitoring phase and placed them in the most interesting areas to collect temperature, humidity, wind speed, and air pollution information. These devices form a network for transmitting data to a central hub for remote observation and data storage.

\section{Results}

Once the morphological/climate indicators were finalized, the macro-scale study turned to the creation of two main cartographic drawings: the Green Atlas and the Risk Map. The former was produced by geospatially relating the DSM and Surface Atlas (Figure 16). A map of urban greenery differentiated by horizontal surfaces (lawns, alluvial areas, etc.) and vertical elements (trees or rather tree masses/canopies) was generated by considering only the green infrastructure and reclassifying the data by height. The canopy cover, average heights of the trees, and all other scientific parameters calculated from measured/simulated data were spatially distributed on hexagons (https:/ / pro.arcgis.com/en/pro-app/tool- 
reference/spatial-statistics/h-whyhexagons.htm accessed on 1 November 2021) of about $350 \mathrm{~m}^{2}$ each, for which the total vulnerability was evaluated quantitatively.

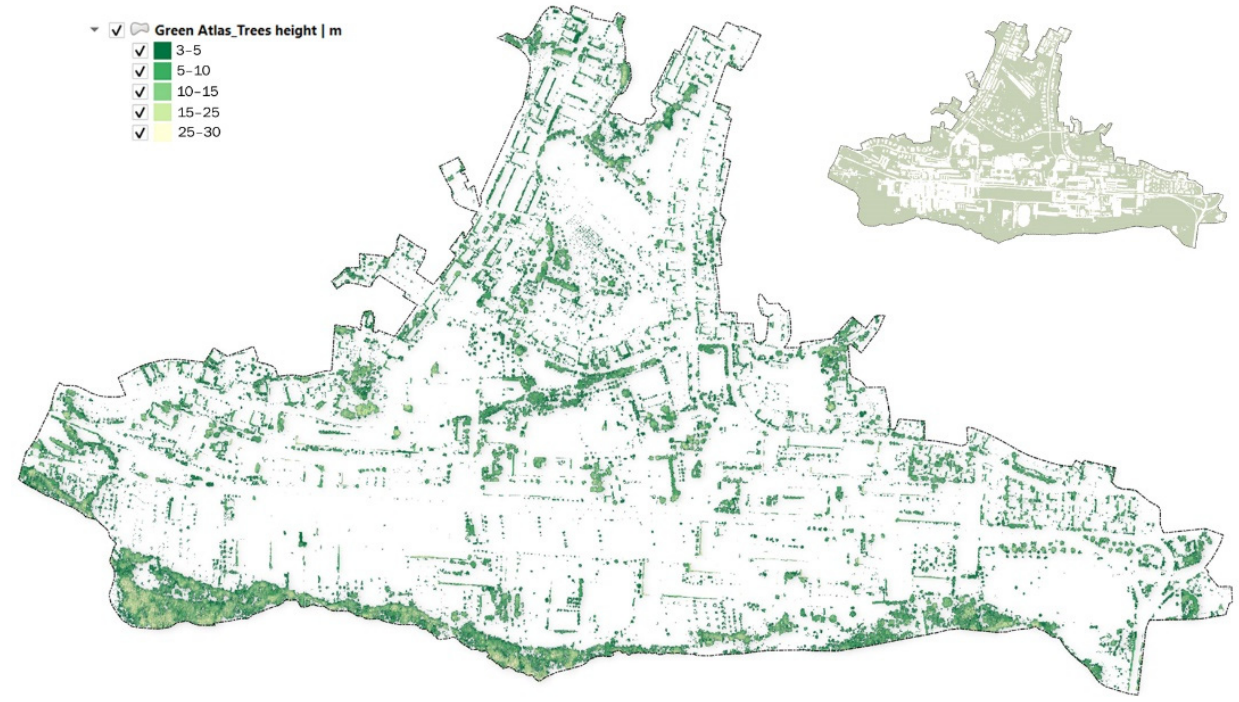

Figure 16. Green Atlas of Monticelli. In the centre, the digital census of trees (SAVI + DSM); at the top right, the 'horizontal' green is identified by the SAVI index.

The entire dataset (Table 4) is configured as the final output of the entire GIS method; specifically, the database correlates each homogeneous spatial entity (hexagon) with multiple numerical or textual parameters expressed as an average or sum referring to morphological, climate, and demographic surveys (Figure 17).

Table 4. The main indicators of the dataset; an excerpt of the quantitative data, referred to hexagon areas subject to risk. * About the summer GR (Jun-Aug); ${ }^{* *}$ about the mean temperature of the three days considered.

\begin{tabular}{|c|c|c|c|c|c|c|c|c|c|c|}
\hline Id_esag & no. Resid. & Under $<18$ & Over > = 65 & $\begin{array}{l}\text { Perm. } \\
\text { m }^{2}\end{array}$ & $\underset{\mathbf{m}^{2}}{\text { Imper. }}$ & $\begin{array}{c}\text { Tree } \\
\text { h.mean }\end{array}$ & $\underset{\mathrm{m}^{2}}{\text { Canopy }}$ & SVF & $\begin{array}{c}\mathrm{GR} \\
\mathrm{kWh} / \mathrm{m}^{2}\end{array}$ & $\begin{array}{l}\text { LST T ** }^{*} \\
\mathrm{~T}^{\circ} \mathrm{C}\end{array}$ \\
\hline 565 & 42 & 5 & 18 & 37.01 & 309.56 & 10.73 & 17.25 & 0.72 & 340.62 & 33.8 \\
\hline 1077 & 66 & 7 & 16 & 83.05 & 263.52 & 3 & 8.81 & 0.74 & 295.05 & 33.8 \\
\hline 3651 & 33 & 5 & 10 & 13.64 & 329.80 & 10.66 & 10.08 & 0.66 & 261.59 & 33.3 \\
\hline 3737 & 37 & 5 & 10 & 45.66 & 300.91 & 11.89 & 16.86 & 0.75 & 342.92 & 33.1 \\
\hline 4012 & 42 & 7 & 10 & 76.66 & 260.95 & 14.25 & 9.38 & 0.68 & 282.38 & 33.4 \\
\hline
\end{tabular}
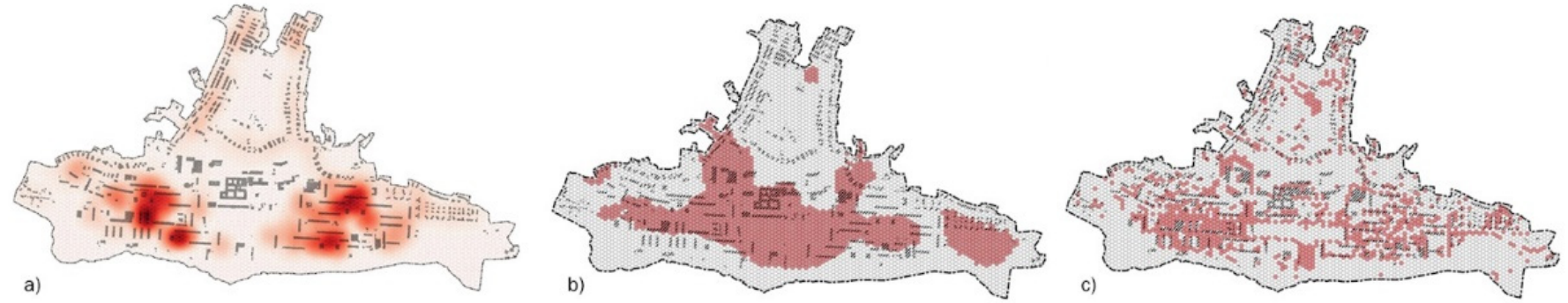

Figure 17. Individual components of neighbourhood vulnerability: (a) social, (b) thermal, (c) grey/green infrastructure.

Before calculating and mapping the risk, the most up-to-date demographic census of Monticelli (2018) was acquired. Free geocoding applications were then used to match each census data point relating to an address with a pair of geographical coordinates $(x, y)$ represented as georeferenced points on the territory.

Finally, the dataset was searched using 'spatial queries' and logical operators to create the 'Urban Risk Map', return graphs of the most vulnerable areas, and develop projects 
based on: (i) an in-depth analysis in a CFD environment and (ii) the collective intangible heritage expressed by the residents during the participatory process (Figure 18). This map combines and returns all qualitative and quantitative information considered to be above the 'critical threshold' on the neighbourhood scale for:

1. Awareness of the population at risk (minors, elderly people, population density);

2. Climate data (GR, DSR, LST);

3. Urban morphology (SVF, Green and Surface Atlases).

With reference to the areas of investigation identified above for the cognitive microclimatic study, the results of the CFD simulation processes concerning the total bioclimate comfort and the various competing variables are reported below (Figures 19-21). The values of potential temperature range from about $20^{\circ} \mathrm{C}$ in open areas to $28.6{ }^{\circ} \mathrm{C}$ in urban areas. Surface temperatures peak at $50.4{ }^{\circ} \mathrm{C}$ at surfaces with a low albedo (e.g., asphalt) and are lowest at natural surfaces. The average radiant temperature is only moderated in trees where the minimum value is around $33^{\circ} \mathrm{C}$; elsewhere, it rises to around $64{ }^{\circ} \mathrm{C}$. Relative humidity values are also related to greenery, where it reaches almost $66 \%$, whereas it drops to $46.6 \%$ in urbanized areas. The wind field has maximum values of $3.2 \mathrm{~m} / \mathrm{s}$ in the most exposed areas (in line with the initial data), and, in the presence of buildings, there is a calm wind. Lastly, the UTCI comfort index, which summarizes the above values, ranges from a minimum of $23.8^{\circ} \mathrm{C}$ to $37.1^{\circ} \mathrm{C}$. The results are summarized in Table 5.

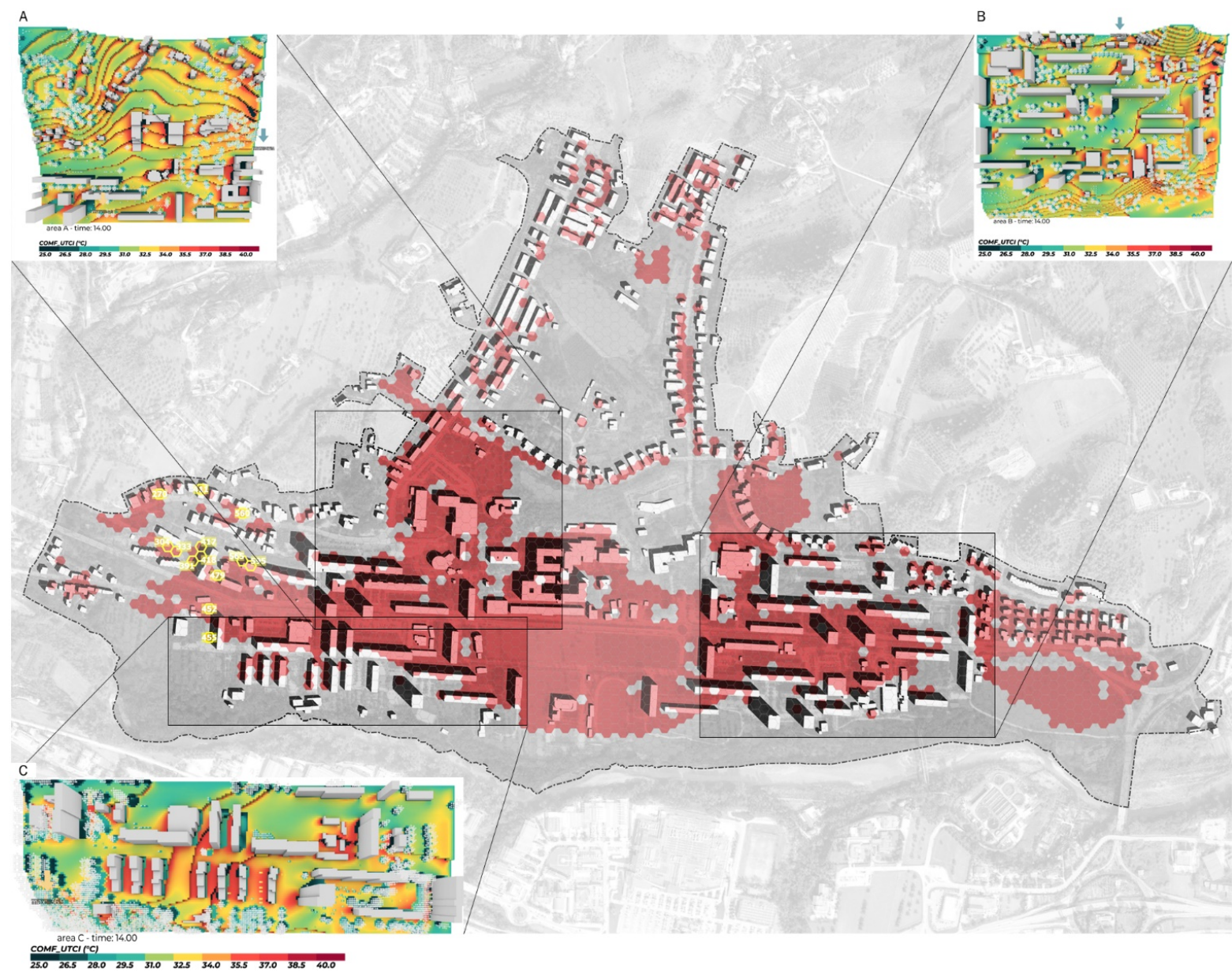

Figure 18. The combined GIScience-CFD simulations approach: from the Urban Risk Map investigation to the CFD micro in-depth analysis simulations (A-C ENVI-met areas). Base map source: Google Maps. 

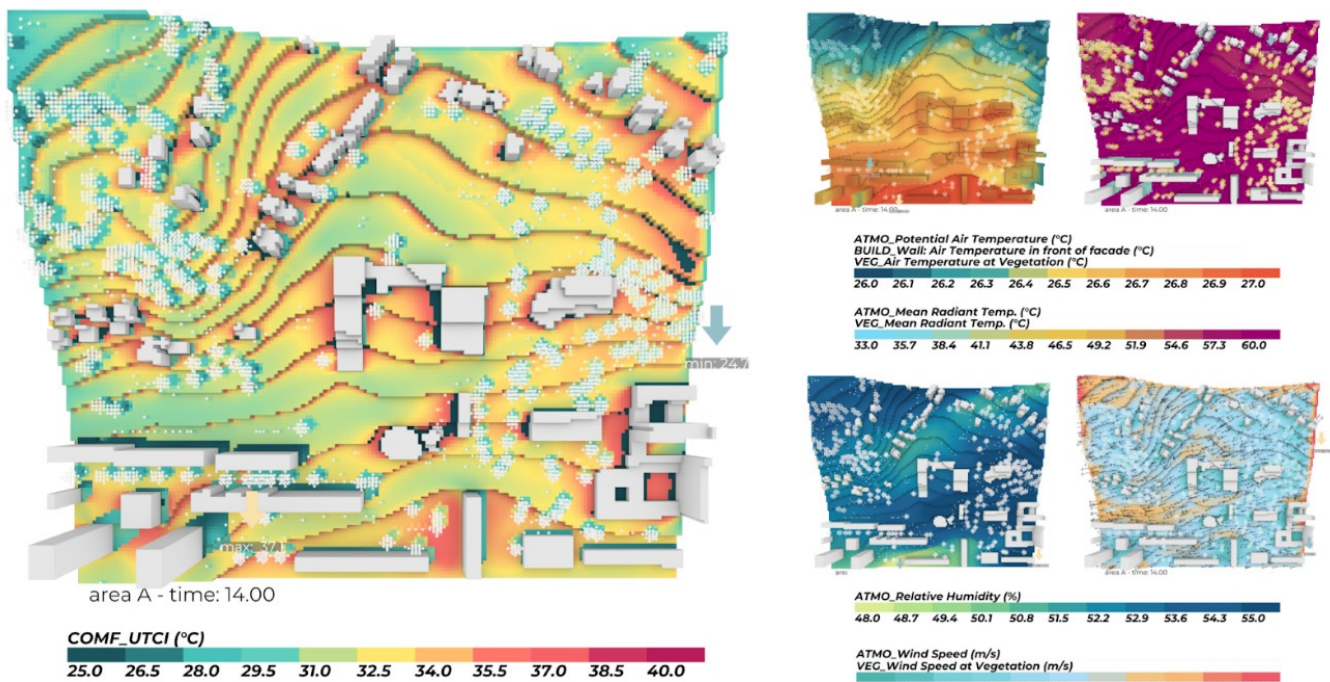

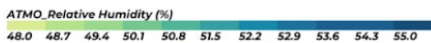

ATMO Wind Speed $(\mathrm{m} / \mathrm{s})$
$\mathrm{VEC}$ W. Wind Speed ot Vegetotion $(\mathrm{m} / \mathrm{s})$
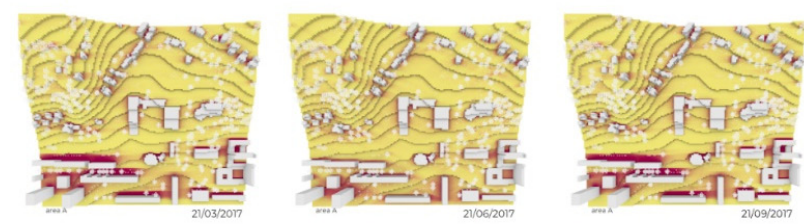

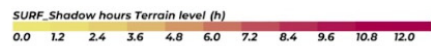
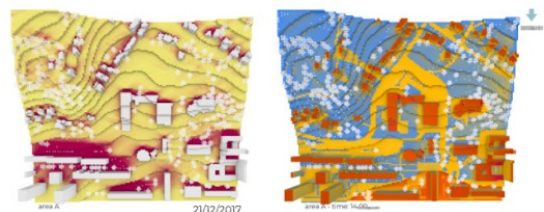

BullD Wall:-Temperature Node $1 /$ outside ('C)
SURF_.T Surfoce (C)

$\begin{array}{llllllllllllll}20.0 & 24.0 & 28.0 & 32.0 & 36.0 & 40.0 & 44.0 & 48.0 & 52.0 & 56.0 & 60.0\end{array}$

Figure 19. ENVI-met results for area A at 14:00.
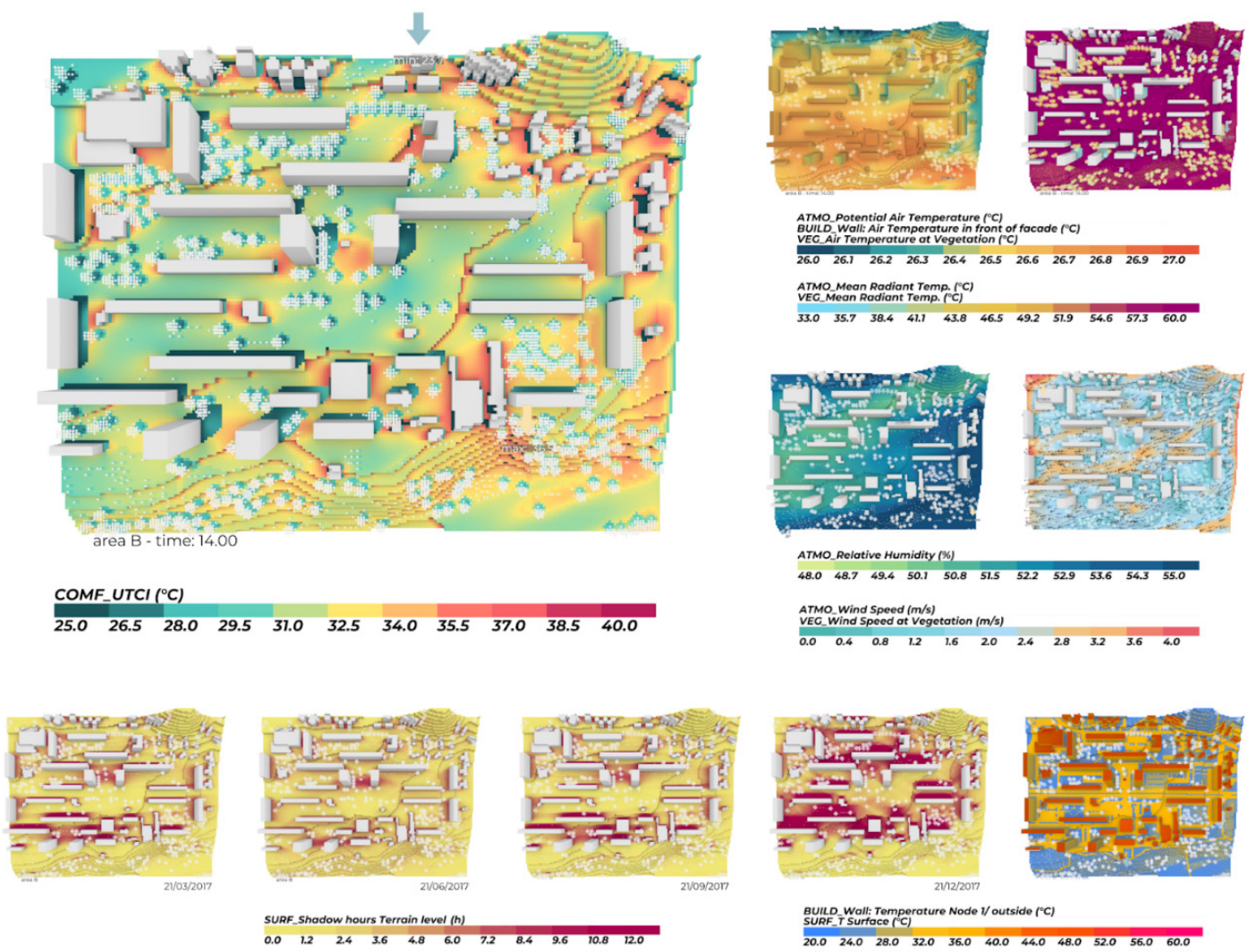

BUILD-Wall: Temperature Node $1 /$ outside ('C)
SURF-T Surface (C)

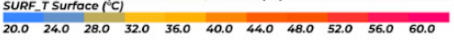

Figure 20. ENVI-met results for area B at 14:00. 


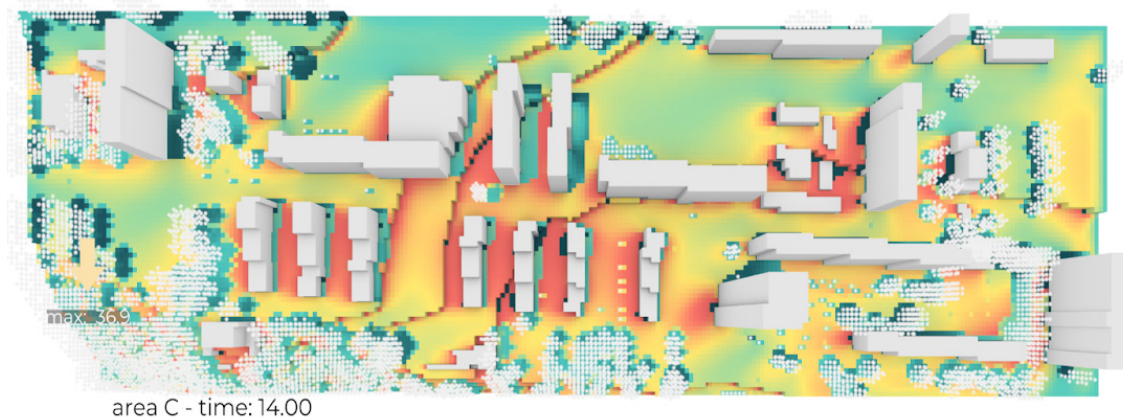

COMF_UTCI $\left({ }^{\circ} \mathrm{C}\right)$

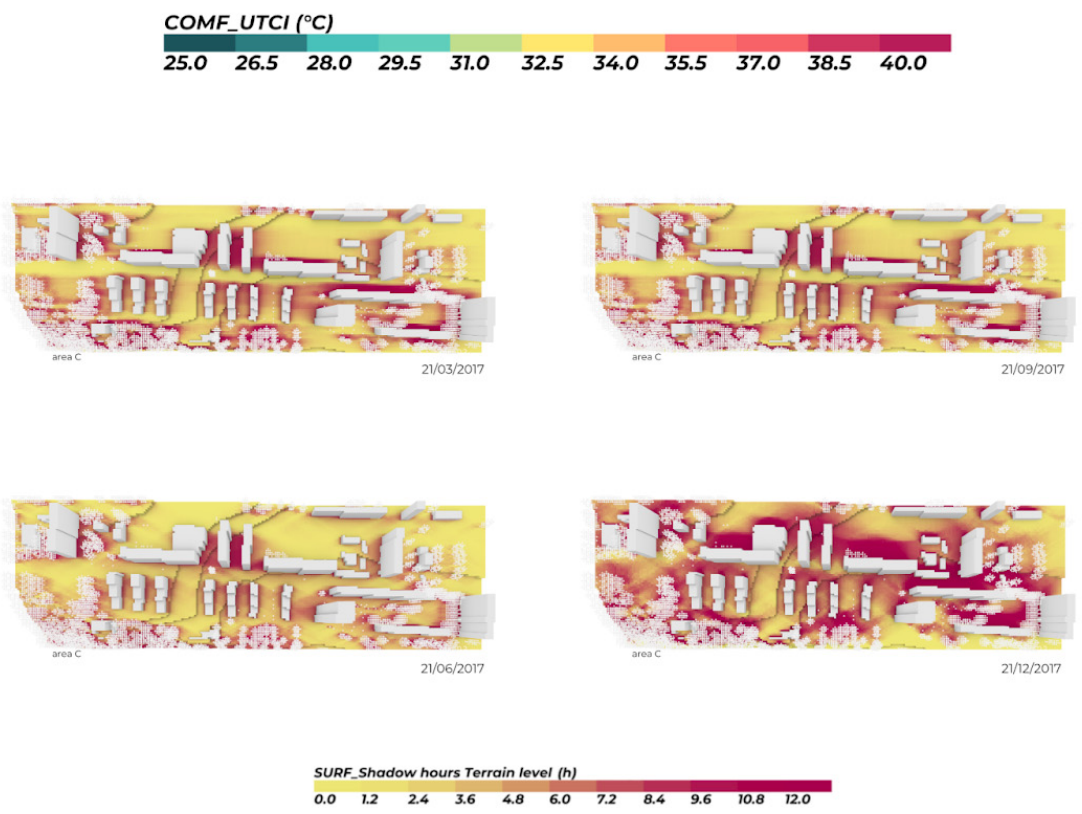

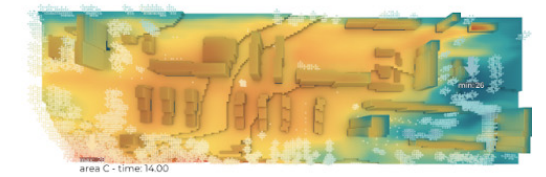
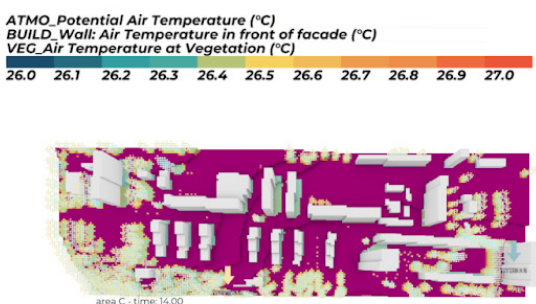

ATMO Mean Radiant Temp. $\left({ }^{\circ} \mathrm{C}\right)$
VEC_Mean Radiant Temp. $\left({ }^{\circ} C\right)$

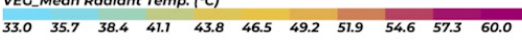

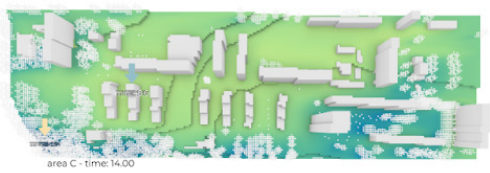

ATMO Relative Humidity (\%) $\begin{array}{lllllllllll}48.0 & 48.7 & 49.4 & 50.1 & 50.8 & 51.5 & 52.2 & 52.9 & 53.6 & 54.3 & 55.0\end{array}$

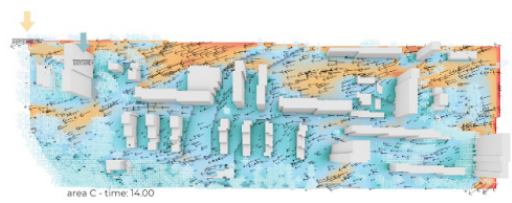

ATMO_Wind Speed ( $\mathrm{m} / \mathrm{s})$
VEC Wind Speed at Vegetation $(\mathrm{m} / \mathrm{s})$
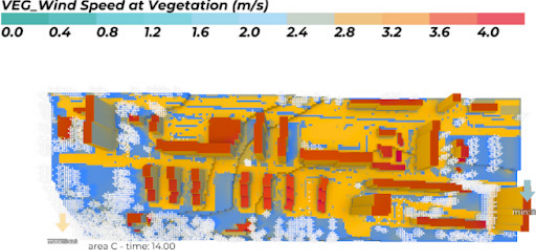

BUILD Wall: Temperature Node $1 /$ outside ( ${ }^{\circ} \mathrm{C}$ )
SURF_T Surface ('C)

$\begin{array}{lllllllllll}20.0 & 24.0 & 28.0 & 32.0 & 36.0 & 40.0 & 44.0 & 48.0 & 52.0 & 56.0 & 60.0\end{array}$

Figure 21. ENVI-met results for area $C$ at 14:00.

Table 5. Minimum and maximum results in the ENVI-met process for all areas at 14:00.

\begin{tabular}{ccccccc}
\hline & Area A Min & Area A Max & Area B Min & Area B Max & Area C Min & Area C Max \\
\hline Potential air temp. $\left({ }^{\circ} \mathrm{C}\right)$ & 20.2 & 28.6 & 20.1 & 26.9 & 26 & 28 \\
Mean radiant temp. $\left({ }^{\circ} \mathrm{C}\right)$ & 35.4 & 62.9 & 33.9 & 61.9 & 33.1 & 63.9 \\
Relative humidity $(\%)$ & 46.6 & 65.9 & 49.7 & 62.9 & 46.6 & 64.9 \\
Wind speed $(\mathrm{m} / \mathrm{s})$ & 0 & 2.2 & 0 & 3.2 & 0 & 2.8 \\
Surface temperature $\left({ }^{\circ} \mathrm{C}\right)$ & 19.6 & 50.4 & 19.9 & 35.3 & 19.8 & 37.1 \\
\hline
\end{tabular}

\section{Discussion}

The topological search of the database revealed a system at risk. It consists of open and residential spaces distributed mainly along the central east-west axis of the neighbourhood and features intensive buildings, large impervious areas, and vacant areas that can potentially be reconfigured.

As can be seen from the three diagrams extracted individually by topic ('social vulnerability', 'heat stress', 'danger from cloudbursts and heat waves'), the large central area of the 
neighbourhood is more inhabited by vulnerable groups, more prone to heat accumulation, and more artificial than other areas. In fact, in the western end towards the centre of Ascoli, many areas are potentially exposed to the impacts of extreme events due to widespread impermeability (paved parking areas), absence/shortage of trees, or presence of exposed and sun-drenched open spaces.

As with all studies developed from more or fewer aggregate data and then reprocessed mainly using semi-automatic techniques, some limitations relating to the quality of the input data can be highlighted. In this sense, some agricultural areas, for example, are 'at risk' due to excessive radiation or because they had no crops when the satellite picture was taken; therefore, they are identified as having low vegetative strength by the SAVI [36] Index and considered 'impermeable'.

Evaluations should be limited to urbanized areas only to avoid this type of error. In this case, the individual spatial unit (hexagon) should be associated with the intended use from other types of studies at the appropriate scales so that the final query can be better filtered automatically.

Regarding the analysis of the data obtained during the simulation phase, it is clear how the differences in surface temperature are correlated with the characteristics of the materials distributed on the ground (Figures 19-21).

The highest temperatures are recorded for impermeable surfaces, about $8{ }^{\circ} \mathrm{C}$ higher than permeable surfaces at the hottest times. In areas where tall vegetation is present, there is a particular cooling effect on surface temperatures, where the temperature is up to $12{ }^{\circ} \mathrm{C}$ less than asphalted surfaces. As with surface temperatures, air temperatures are also higher in the most urbanized areas, gradually decreasing in less urbanized areas. In the same areas where the air temperature is higher, the wind speed is halved due to the characteristics of the built area. The correlation of these characteristics results in a low level of comfort in the area, as can be verified in the UTCI (universal thermal climate index) comfort map. The temperatures obtained are above optimal and normally in the $19-26{ }^{\circ} \mathrm{C}$ range. It can be seen that zones are created near vegetation where the perceived temperature reaches $28^{\circ} \mathrm{C}$, which is still above but much closer to the comfort range than in urbanized areas. The area close to the Tronto River clearly shows the highest humidity values. Here, perceived temperatures exceed $35^{\circ} \mathrm{C}$.

Thermal fluid dynamics analyses are now well established within the context of this research. However, they can benefit from preliminary analysis in a GIS environment, which yields essential information to streamline the enormous data-processing procedure typical of CFD analyses. With this method, attention focused mainly on specific points in the Monticelli neighbourhood. It allowed for an understanding of how the materials of the horizontal surfaces, the presence of trees, and the conformation and distribution of the building system have the most significant influence on comfort levels. Therefore, these elements require greater attention in the decision-making phase when redeveloping the area.

Despite some approximations, the research allowed for experimentation with an integrated workflow involving various disciplines, from town planning to climatology, from agroecology to geography and from geomatics to computer science, to objectively characterize the territory using a scientific, transcalar, and multidisciplinary approach.

\section{Conclusions}

This paper presented an integrated workflow to construct maps and urban risk and vulnerability scenarios on various scales and with different techniques involving data extraction/processing and new geo-information production (e.g., Green Atlas, etc.).

In this sense, the research aims to renew the cognitive tools used for urban and city planning. However, it is useful to highlight how this contribution aims to go beyond the innovation of cognitive processes, underlining how the CCUHRE project in its entirety considers the integration of technical and local knowledge as real added value. 
In this perspective, there is an urgent need to offer opportunities for direct interaction between different types of expert knowledge and experiential/local/mixed knowledge to establish an in-depth cognitive framework for evaluating the city and its environmental, social, and health emergencies.

Starting from the compiled technological geo-dataset, semi-automatic methods were used to identify priority areas targeted by further investigations better related to the perception of comfort and the complex thermal fluid dynamic interactions that characterize the city system. Therefore, this combinatory study of GIScience and CFD arises as an experiment in trans-scale and multidisciplinary methods to support future designs and adaptive solutions. The strength of such risk maps and CFD micro-analysis simultaneously shows the critical and planning systems, which, reinterpreted in the municipal urban agenda and social demands, can be reconfigured as a structural layout responding to urban fragility and citizen needs. These solutions can be tested virtually digitally in future research to evaluate their effectiveness concerning the space-time component, thermal well-being related to representative days, the 'performance' nature of vegetation, etcetera.

The future developments of this and other research will be able to evaluate the efficiency of the proposed solutions through pre-figurative-alternative scenarios. These evolutionary scenarios will measure thermo-regulatory actions related to energy efficiency or greening strategies (e.g., desealing, micro-forestation, rain gardens, green roofs, cool and high albedo/reflectance materials, etc.) as tested on various scales in several GIScience or ENVI-met studies [5,44-47]. On the other hand, they will be completed with aestheticperceptive and socio-recreational analyses through an integrated, technological-traditional approach as developed in CCUHRE project.

Today, contingent emergencies require cross-cutting knowledge, targeted investments, and quality projects. Incremental proposals for territorial safety will have to enhance and protect the landscape and sustainably manage building processes, considering the life cycles of the individual components, whether artificial or natural, from macro to micro, from local to global, and vice versa. The strategies described herein help to define precise systemic actions integrated with local centralities and slow mobility within/outside the neighbourhood. The newly designed infrastructure will adapt over time to contingent climate criticalities that impact services, biodiversity, and ecological connectivity and the perception of mental/physical well-being, offering opportunities for recreation and cooperation to increase the quality of life in Monticelli.

Author Contributions: R.C.G. oversaw the methodological and conceptual setting of the work presented by supervising and validating the text and data results during the research phases. The co-authors G.C. and G.E.M. provided the formal analysis of the data, their collection, processing, and graphic display. All authors declare that they collaborated in writing this contribution. All authors have read and accepted the version of the submitted manuscript.

Funding: This research was funded by Camerino University as FAR project (Fondi-Ateneo-Ricerca) CCUHRE (Climate Change and Urban Health Resilience) 2018-2021.

Institutional Review Board Statement: Not applicable.

Informed Consent Statement: Not applicable.

Data Availability Statement: The data presented in this study are available by request.

Acknowledgments: This work owes great thanks to the UNICAM Research Group for the collaboration and the internal departments of the City of Ascoli Piceno for technical support.

Conflicts of Interest: The authors declare no conflict of interest.

\section{References}

1. Santamouris, M.; Kolokotsa, D. On the Impact of urban overheating and extreme climatic conditions on housing, energy, comfort and environmental quality of vulnerable population in Europe. Energy Build. 2015, 98, 125-133. [CrossRef]

2. Beg, N.; Morlot, J.C.; Davidson, O.; Afrane-Okesse, Y.; Tyani, L.; Denton, F.; Sokona, Y.; Thomas, J.P.; Rovere, E.L.L.; Parikh, J.K.; et al. Linkages between climate change and sustainable development. Clim. Policy 2002, 2, 129-144. [CrossRef] 
3. Acero, J.A.; Herranz-Pascual, K. A Comparison of thermal comfort conditions in four urban spaces by means of measurements and modelling techniques. Build. Environ. 2015, 93, 245-257. [CrossRef]

4. Akbari, H.; Cartalis, C.; Kolokotsa, D.; Muscio, A.; Pisello, A.L.; Rossi, F.; Santamouris, M.; Synnef, A.; Wong, N.H.; Zinzi, M. Local climate change and urban heat island mitigation techniques-The state of the art. J. Civ. Eng. Manag. 2016, 22, 1-16. [CrossRef]

5. Detommaso, M.; Gagliano, A.; Marletta, L.; Nocera, F. Sustainable urban greening and cooling strategies for thermal comfort at pedestrian level. Sustainability 2021, 13, 3138. [CrossRef]

6. Heaviside, C.; Macintyre, H.; Vardoulakis, S. The urban heat island: Implications for health in a changing environment. Curr. Environ. Health Rep. 2017, 4, 296-305. [CrossRef]

7. Talia, M. Le Nuove Comunità Urbane e Il Valore Strategico Della Conoscenza Atti Della Conferenza Internazionale UrbanPromo XVII Edizione. Available online: http://www.planum.net/atti-conferenza-urban-promo-xvii-2020 (accessed on 29 December 2021).

8. Ballatore, A.; De Sabbata, S. Charting the geographies of crowdsourced information in greater London. In Geospatial Technologies for All; Mansourian, A., Pilesjö, P., Harrie, L., van Lammeren, R., Eds.; Springer International Publishing: Cham, Switzerland, 2018; pp. 149-168.

9. Sharma, P.; Singh, R.; Srivastava, A. Analyzing the role of geospatial technology in smart city development. In Geospatial Technology and Smart Cities: ICT, Geoscience Modeling, GIS and Remote Sensing; Sharma, P., Ed.; The Urban Book Series; Springer International Publishing: Cham, Switzerland, 2021; pp. 1-20, ISBN 978-3-030-71945-6.

10. Wilson, E.O. GIS for Science, Volume 3: Maps for Saving the Planet; Wright, D.J., Harder, C., Eds.; Esri Press: Redlands, CA, USA, 2021; ISBN 978-1-58948-671-3.

11. Antoniou, N.; Montazeri, H.; Neophytou, M.; Blocken, B. CFD simulation of urban microclimate: Validation using high-resolution field measurements. Sci. Total Environ. 2019, 695, 133743. [CrossRef]

12. Medved, S. Urban Environment and local climate. In Building Physics: Heat, Ventilation, Moisture, Light, Sound, Fire, and Urban Microclimate; Medved, S., Ed.; Springer Tracts in Civil Engineering; Springer International Publishing: Cham, Switzerland, 2022; pp. 453-472, ISBN 978-3-030-74390-1.

13. Belpoliti, V.; Altan, H.; Alsebai, H.; Melahfci, O. Shaping the microclimate: CFD-assisted design optimization to enhance the outdoor comfort of a recreational complex in the UAE. Procedia Manuf. 2020, 44, 84-91. [CrossRef]

14. Ejiagha, I.R.; Ahmed, M.R.; Hassan, Q.K.; Dewan, A.; Gupta, A.; Rangelova, E. Use of remote sensing in comprehending the influence of urban landscape's composition and configuration on land surface temperature at neighbourhood scale. Remote Sens. 2020, 12, 2508. [CrossRef]

15. Hofierka, J.; Gallay, M.; Onačillová, K.; Hofierka, J. Physically-based land surface temperature modeling in urban areas using a 3-d city model and multispectral satellite data. Urban Clim. 2020, 31, 100566. [CrossRef]

16. Brownlee, T.; Camaioni, C.; Pellegrino, P. Emergenza Clima e Qualità Della Vita Nelle Città; FrancoAngeli: Milan, Italy, 2021; ISBN 978-88-351-0907-5.

17. Busato, F.; Lazzarin, R.M.; Noro, M. Three years of study of the urban heat island in padua: Experimental results. Sustain. Cities Soc. 2014, 10, 251-258. [CrossRef]

18. Detommaso, M.; Costanzo, V.; Nocera, F. Application of weather data morphing for calibration of urban ENVI-met microclimate models. Results and critical issues. Urban Clim. 2021, 38, 100895. [CrossRef]

19. Noro, M.; Lazzarin, R. Urban heat island in padua, italy: Simulation analysis and mitigation strategies. Urban Clim. 2015, 14, 187-196. [CrossRef]

20. Tirabassi, T.; Nassetti, S. The representative day. Atmos. Environ. 1999, 33, 2427-2434. [CrossRef]

21. Grifoni, R.C.; Pierantozzi, M.; Tascini, S.; Passerini, G. Assessing the Representativeness of Thermal Comfort in Outdoor Spaces; WIT Transactions on Ecology and the Environment; WIT Press: Ancona, Italy, 2012; pp. 835-846.

22. Rosenzweig, C.; Solecki, W.D.; Romero-Lankao, P.; Mehrotra, S.; Dhakal, S.; Ibrahim, S.A. (Eds.) Climate Change and Cities: Second Assessment Report of the Urban Climate Change Research Network, 1st ed.; Cambridge University Press: Cambridge, UK; New York, NY, USA, 2018; ISBN 978-1-316-60333-8.

23. Spano, D.; Mereu, V.; Bacciu, V.; Marras, S.; Trabucco, A.; Adinolfi, M.; Barbato, G.; Bosello, F.; Breil, M.; Buonocore, M.; et al. Analisi del Rischio. I Cambiamenti Climatici in Italia; Fondazione CMCC—Centro Euro-Mediterraneo sui Cambiamenti Climatici: Lecce, Italy, 2020.

24. Füssel, H.-M.; Marx, A.; Hildén, M.; Bastrup-Birk, A.; Louwagie, G.; Wugt-Larsen, F.; Suk, J. Climate Change, Impacts and Vulnerability in Europe 2016; European Environment Agency: København, Denmark, 2017; ISBN 978-92-9213-835-6.

25. AR5 Climate Change 2014: Impacts, Adaptation, and Vulnerability; IPCC: Geneva, Switzerland, 2014.

26. Aslam, A.; Rana, I.A.; Bhatti, S.S. The spatiotemporal dynamics of urbanisation and local climate: A case study of Islamabad, Pakistan. Environ. Impact Assess. Rev. 2021, 91, 106666. [CrossRef]

27. Jurgilevich, A.; Räsänen, A.; Juhola, S. Assessing the dynamics of urban vulnerability to climate change: Case of Helsinki, Finland. Environ. Sci. Policy 2021, 125, 32-43. [CrossRef]

28. Bröde, P.; Krüger, E.; Rossi, F. Assessment of Urban Outdoor Thermal Comfort by the Universal Thermal Climate Index UTCI. In Proceedings of the 14th International Conference on Environmental Ergonomics, Nafplion, Greece, 10-15 July 2011. 
29. Fiala, D.; Havenith, G.; Bröde, P.; Kampmann, B.; Jendritzky, G. UTCI-fiala multi-node model of human heat transfer and temperature regulation. Int. J. Biometeorol. 2012, 56, 429-441. [CrossRef]

30. Havenith, G.; Fiala, D.; Blazejczyk, K.; Richards, M.; Broede, P.; Holmer, I.; Rintamaki, H.; Benshabat, Y.; Jendritzky, G. The UTCI-clothing model. Int. J. Biometeorol. 2012, 56, 461-470. [CrossRef]

31. ENVI-Met-Decode Urban Nature with Microclimate Simulations. Available online: https://www.envi-met.com/ (accessed on 29 December 2021).

32. Chatzinikolaou, E.; Chalkias, C.; Dimopoulou, E. Urban microclimate improvement using ENVI-met climate model. Int. Arch Photogramm. Remote Sens. Spatial Inf. Sci. 2018, 19, 69-76. [CrossRef]

33. Naboni, E.; Coccolo, S.; Meloni, M.; Scartezzini, J.-L. (Eds.) Outdoor comfort simulation of complex architectural designs: A review of simulation tools from the designer perspective. In Proceedings of the 2018 Building Performance Analysis Conference and SimBuild co-organized by ASHRAE and IBPSA-USA, Chicago, IL, USA, 26-28 September 2018.

34. Simon, H.; Bruse, M. Modelling of microclimates. In Eco-Design of Buildings and Infrastructure; CRC Press: Boca Raton, FL, USA, 2020; ISBN 978-1-00-309507-1.

35. D'Onofrio, R.; Trusiani, E. The ascoli piceno case: The CCUHRE project. In Urban Health: Participatory Action-Research Models Contrasting Socioeconomic Inequalities in the Urban Context; Battisti, A., Marceca, M., Iorio, S., Eds.; Green Energy and Technology; Springer International Publishing: Cham, Switzerland, 2020; pp. 113-146. ISBN 978-3-030-49446-9.

36. Huete, A.R. A soil-adjusted vegetation index (SAVI). Remote Sens. Environ. 1988, 25, 295-309. [CrossRef]

37. Coelho, A.L.N.; Correa, W.D.S.C. Temperatura de Superfície Celsius do Sensor TIRS/Landsat-8: Metodologia e aplicações. Rev. Geográfica Acadêmica 2013, 7, 31-45. [CrossRef]

38. Anandababu, D.; Purushothaman, B.M.; Suresh Babu, S. Estimation of land surface temperature using LANDSAT 8 data. J. Adv. Res. 2018, 4, 177-186.

39. Oke, T.R. Towards better scientific communication in urban climate. Theor. Appl. Climatol. 2006, 84, 179-190. [CrossRef]

40. Oke, T.R.; Mills, G.; Christen, A.; Voogt, J.A. Urban Climates; Cambridge University Press: Cambridge, UK, 2017; ISBN 978-0-52184950-0.

41. ASSAM Regione Marche-Centro Operativo di Agrometereologia Regione Marche. Analisi Clima 2017. 2017. Available online: http:/ / www.meteo.marche.it/news/anno2017/clima2017.pdf (accessed on 1 November 2021).

42. Kleerekoper, L.; van Esch, M.; Salcedo, T.B. How to make a city climate-proof, addressing the urban heat island effect. Resour. Conserv. Recycl. 2012, 64, 30-38. [CrossRef]

43. Ottone, M.F.; Grifoni, R.C.; Marchesani, G.E. Mass and lightness: Urban quality along the Aurelian Walls in Rome. Walking through walls. TECHNE-J. Technol. Archit. Environ. 2020, 19, 280-289. [CrossRef]

44. Liu, Z.; Cheng, W.; Jim, C.Y.; Morakinyo, T.E.; Shi, Y.; Ng, E. Heat mitigation benefits of urban green and blue infrastructures: A systematic review of modeling techniques, validation and scenario simulation in ENVI-met V4. Build. Environ. 2021, $200,107939$. [CrossRef]

45. Buccolieri, R.; Gatto, E.; Manisco, M.; Ippolito, F.; Santiago, J.L.; Gao, Z. Characterization of urban greening in a district of lecce (southern Italy) for the analysis of $\mathrm{CO}_{2}$ storage and air pollutant dispersion. Atmosphere 2020, 11, 967. [CrossRef]

46. Gatto, E.; Buccolieri, R.; Aarrevaara, E.; Ippolito, F.; Emmanuel, R.; Perronace, L.; Santiago, J.L. Impact of urban vegetation on outdoor thermal comfort: Comparison between a mediterranean city (Lecce, Italy) and a northern European city (Lahti, Finland). Forests 2020, 11, 228. [CrossRef]

47. Lindberg, F.; Grimmond, C.S.B.; Gabey, A.; Huang, B.; Kent, C.W.; Sun, T.; Theeuwes, N.E.; Järvi, L.; Ward, H.C.; Capel-Timms, I.; et al. Urban multi-scale environmental predictor (UMEP): An integrated tool for city-based climate services. Environ. Model. Softw. 2018, 99, 70-87. [CrossRef] 